Cruz, L., Rodríguez, D. (2016). Calidad de vida de mujeres rurales jefes de hogar de familias monoparentales en la vereda La Llanerita de Villavicencio, Meta. Revista Lebret, 8. Bucaramanga, Colombia: Universidad Santo Tomás, pp. 203 -239 . ISSN: $2145-5996$

\title{
Calidad de vida de mujeres rurales jefes de hogar de familias monoparentales en la vereda La Llanerita de Villavicencio, Meta*
}

\section{Quality of life of rural women-heads of single parent families in Llanerita Village of Villavicencio-Meta Department}

Lina Constanza Cruz Rodríguez

Diana Carolina Rodríguez Pabón ${ }^{2}$

\begin{abstract}
Resumen
El presente artículo analiza las condiciones de calidad de vida de las mujeres rurales con jefatura femenina de familias monoparentales, de la vereda La Llanerita del municipio de Villavicencio basadas en las diez capacidades básicas humanas, planteadas por Martha Nussbaum (2002). A partir de estas capacidades se formularon indicadores con posibilidades de aplicabilidad en mujeres rurales de diversos contextos del territorio nacional. Se construyó una metodología mixta. Algunas deducciones evidenciaron que las mujeres tienen bajas condiciones de calidad de vida resultado de procesos históricos de exclusión, como dificultades para poseer títulos de propiedad de la tierra y para acceder a fuentes de financiación, y realizar de manera continua procesos de educación formal, además ellas mismas no se identifican como mujeres rurales.
\end{abstract}

\section{Palabras clave}

Calidad de vida, mujer rural, capacidades, jefatura femenina, indicadores socioeconómicos.

Código de clasificación JEL: I3, I31, O1,O15,018.

\begin{abstract}
The present article is the result of the investigation quality conditions of life of the rural women with feminine headquarters of single-parent families of the Path the Llanerita of Villavicencio's, whose theoretical base and for his respective analysis they are ten basic human capacities raised by Martha Nussbaum (2002). From these capacities indicators were formulated by possibilities of applicability in rural women of diverse contexts of the National territory. A mixed methodology was constructed. Some results demonstrated that the women have low conditions of quality of life ensued from historical processes of exclusion, as difficulties to possess title deeds of the land, not to have access to financing sources, educational levels with low qualification for the performance in productive own activities of the rural sector, of luck that they themselves do not identify as rural women.
\end{abstract}

\section{Keywords}

Quality of life, rural woman, capacities, feminine headquarters, socioeconomic indicators.

* Artículo derivado del trabajo de grado de la especialización en Planeación, Gestión y Control del Desarrollo Social de la Universidad de la Salle de Bogotá realizado por las autoras.

1 Economista, Universidad de la Salle Bogotá. Correo electrónico: lccr1212@hotmail.com

2 Economista, Universidad de la Salle Bogotá. Correo electrónico: diakers_ro@yahoo.mx 


\section{Aproximaciones teóricas}

\section{Enfoque desarrollo rural}

El desarrollo rural está definido como "un proceso localizado de cambio social y crecimiento económico sostenible, que tiene por finalidad el progreso permanente de la comunidad rural y de cada individuo integrado en ella" (Válcarcel-Resalt, 1995, p. 403).

A su vez, Sancho, Martínez \& Martín (2002) definen el desarrollo rural como: un proceso porque es una acción que tiene una duración y abarca un tiempo determinado. Las características se pueden clasificar como global, participativo, endógeno y subsidiario; y por otro lado tiene unos contenidos: fortalecer la formación del agricultor, potenciar la I+D, mejorar las condiciones de vida, crear empleo, diversificar los recursos económicos y hacer compatible todo ello con la sostenibilidad del medio ambiente (figura 1) (p. 80).

Figura 1. Mapa conceptual desarrollo rural

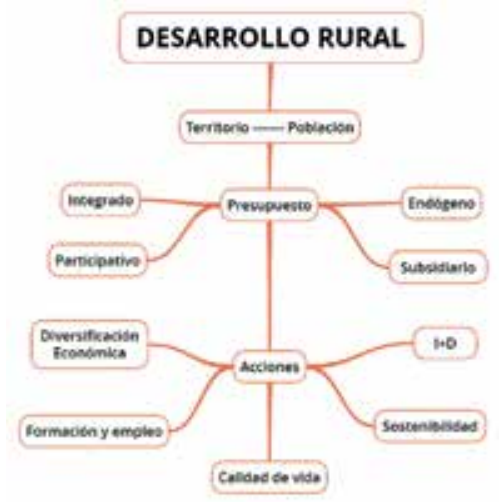

Fuente: Sancho, Martínez \& Martín, 2002.

La clasificación planteada define como global a que ningún territorio debe ser excluido de las políticas sectoriales y deben tener la posibilidad de instaurar allí las estrategias de desarrollo; participativo porque debe tener las iniciativas de todos los miembros de la comunidad, respetando sus iniciativas y los grupos caracterizados. Endógeno porque los cambios, el progreso y el apoyo debe provenir de la misma comunidad o población; y subsidiario porque el apoyo, los subsidios, los incentivos pueden tener origen en fuerzas externas como administraciones públicas o sectores privados; no obstante después de entregar las ayudas los agentes deben actuar como observadores evitando así restarles importancia a los agentes rurales (Sancho, Martínez \& Martín, 2002, pp. 81-83). 
Es conveniente precisar que las acciones, Sancho, Martínez \& Martín (2002) las plantean así:

1. Calidad de vida: debe realizarse bajo una perspectiva triple, infraestructura y servicios necesarios, cohesión económica y social y recuperación del prestigio social y los valores del medio rural ante una sociedad urbana.

2. Creación de empleo: se debe promocionar el empleo en jóvenes, desarrollar una política de ayuda a la mujer y diseñar planes de formación permanente.

3. Diversificación económica: buscar la plurifuncionalidad en los territorios generando diversas ofertas tales como la producción agraria, el recreo y turismo, la agroindustria, la artesanía, la restauración, la valorización ambiental.

4. Sostenibilidad: el desarrollo no debe poner en peligro los recursos para generaciones futuras, sino el desarrollo de la actividad agraria, tener entre sus objetivos cuidar el paisaje y mantener en el espacio natural de algún modo esos valores.

5. I+D: La investigación y el desarrollo de nuevos productos así como la adaptación del mundo agrario a las nuevas tecnologías es fundamental para no generar una brecha con los entornos urbanos e impedir la marginación del espacio rural (Sancho, Martínez \& Martín, 2002, p. 83).

El desarrollo rural ha evolucionado su concepción de la mitigación de la pobreza y hacia una orientación de la visión de lo regional y la sostenibilidad; no solo de los recursos sino también política, cultural, social y económica; de igual forma se incorporó el concepto de empoderamiento de los pobladores rurales y las organizaciones para que puedan ejercer sus derechos frente al Estado; siempre teniendo en cuenta el respeto al medio natural y que no ponga en peligro los recursos para las siguientes generaciones.

\section{Enfoque de género: mujeres}

Como soporte teórico la investigación recurrió a los aportes de Sen (2000), Nussbaum (2002) y Fraser (1997), para abordar los problemas de desigualdad, falta de oportunidades y exclusión social de las mujeres.

Las mujeres se encuentran en todos los ámbitos de la sociedad, muchos las consideran como la base de todas las actividades humanas; su incursión en las diferentes áreas ha generado el cambio hacia una concepción de feminidad enmarcada en la ejecución de actividades mentales, físicas y emocionales. En este documento se abordará el tema de mujer rural; antes de iniciar es necesario definir el término de ruralidad el cual "no es exclusivamente lo agrícola ni la sola expresión de la producción primaria. Lo rural trasciende lo agrario” (Farah \& Pérez, 2003, p. 140). 
El acceso a la educación a las mujeres, la apertura al mercado laboral, conexiones a redes internacionales y la cultura de masas ha permitido cambiar las perspectivas frente a los siglos pasados. Farah \& Pérez (2003) destacan que la revolución sexual trajo consigo la defensa para tomar las decisiones sobre su cuerpo.

No obstante, para hablar de las mujeres es necesario diferenciar el concepto de género y la diferencia sexual; el primer término refiere a las ideas, representaciones, atribuciones y prescripciones sociales, mientras que el segundo término representa a las diferencias biológicas entre hombres y mujeres, especialmente las diferencias genitales y el papel que cada uno desempeña en lo reproductivo. Pero este no es únicamente un factor para diferenciar, también se debe realizar diferenciaciones cultural-valorativa que incluye elementos que se asemejan más a la sexualidad que a los de clase.

Algunas injusticias de género son el androcentrismo, el cual se constituye como una serie de normas que privilegian a la masculinidad; el sexismo cultural que es la devaluación representada en ataques sexuales, explotación sexual y la violencia doméstica; discriminación en las actitudes; exclusión o marginación en las esferas públicas y la negación de los derechos legales y de igual protección.

Actualmente la lucha por la igualdad de género aún es un tema recurrente en las decisiones gubernamentales, no se han cumplido los objetivos ni se ha logrado una inclusión total. Fraser (1997) propone que se hace necesario construir debates en torno a la igualdad social y la diferencia cultural, desarrollar visiones multiculturales de la pluralidad y combinar la lucha por el multiculturalismo antiesencialista con la lucha por la igualdad social.

En el artículo 43 de la Constitución Política Colombiana se hace explícita la protección del Estado colombiano a la mujer cabeza de familia:

la mujer y el hombre tienen iguales derechos y oportunidades. La mujer no podrá ser sometida a ninguna clase de discriminación durante el embarazo y después del parto gozará de esencial asistencia y protección del Estado, y recibirá de este subsidio alimentario si entonces estuviere desempleada o desamparada. El Estado apoyará de manera especial a la mujer cabeza de familia.

En Colombia el movimiento social de mujeres logró por primera vez en la historia del país que se incluyera explícitamente a 'la mujer' y la no-discriminación por razones de sexo en los artículos 13 y 43 de la Constitución Política Colombiana de 1991. Por otro lado, la Ley 30 de 1988 es la primera ley de reforma agraria en la historia colombiana en que las mujeres campesinas obtienen la titulación de la tierra de la pareja, a partir de los 16 años; el logro legal más reciente de las mujeres del campo es la Ley 731 de enero de 2002, primera en la historia que se dirige exclusivamente a las mujeres rurales. Las mujeres luchan por mejores condiciones de vida y de derechos para ellas y en proyección para la población colombiana. Es decir, el panorama de luchas de las mujeres alienta las posibilidades de una situación digna y justa para colombianos y colombianas. 
Se han trascendido las fronteras del espacio doméstico, del rural y del nacional y se han obtenido logros de distintos órdenes y en distintas magnitudes priorizando mediante el compromiso activo con el empoderamiento de las mujeres rurales para la construcción y vigencia de su ciudadanía y compartir las obligaciones domésticas con los demás miembros de la familia; involucrar explícitamente la consecución de condiciones cotidianas de bienestar de mujeres y hombres campesinos, en sus espacios y roles tanto privados (domésticos), como públicos (producción y mercado); convocando a los medios masivos de comunicación a hacer campañas en las regiones, las localidades y las comunidades sobre los derechos de las mujeres, contra la violencia intrafamiliar y por la defensa del campesinado (Díaz, 2002).

Algunos indicadores muestran que a) el 50\% de las mujeres rurales tiene menos de primaria o ninguna educación. b) la participación de la población femenina rural en el desempleo es importante, y además las mujeres rurales enfrentan una discriminación en su retribución económica. c) los hogares con jefatura femenina (19\% de los hogares rurales), tienen una mayor proporción en la pobreza y la indigencia (Farah y Pérez, 2003).

A pesar de la responsabilidad laboral, que ella misma dice tener, la mujer se ve enfrentada a conflictos laborales, los que incluso han terminado en humillaciones en el interior de su trabajo, situación que ha soportado, a pesar de la inconformidad laboral, debido a sus necesidades. A pesar de estas situaciones, en las cuales las mujeres se ven enfrentadas a condiciones de trabajo aun precarias, con relaciones laborales inestables y con escasa protección de seguridad social, el tener un trabajo contribuye al progreso de las mujeres respecto de sus condiciones previas. Uno de los temores que enfrentan las mujeres es el ser despedidas o poder llegar a puestos más altos en sus trabajos, y cuando esto último se logra, viene el conflicto de conciliar el desempeño laboral y el cuidado de los hijos (Escamilla, Parra, Sepúlveda \& Vásquez, 2013).

Las mujeres parecen ser más vulnerables en el momento del desarraigo, expuestas intempestivamente a la viudez, las amenazas, la clandestinidad, la huida, el quiebre de relaciones primarias organizadas entorno a lo doméstico, en fin, al abandono familiar, físico y social (Segura \& Meerten, 1997).

\section{Enfoque familias}

Teniendo en cuenta que nuestras sociedades están ligadas a las familias, tradicionalmente se ha determinado que en el núcleo familiar existe un jefe de hogar que puede ser hombre o mujer, el cual es reconocido por los demás miembros como aquel o aquella que toma las decisiones y aporta económicamente.

Con respecto a esto la Comisión Económica para América Latina y el Caribe (CEPAL, 2015) señaló que: 
Los arreglos familiares se han diversificado. Los hogares nucleares biparentales pasaron de un $52,1 \%$ a un $41,8 \%$ y los hogares nucleares monoparentales con jefatura femenina han aumentado del $7,4 \%$ al $10,2 \%$. Es más, los conjuntos de hogares familiares con jefatura femenina, tanto nucleares como extensos, pasó de representar el $12,3 \%$ al $15,8 \%$.

Es decir, el tamaño medio de las familias se ha reducido por la disminución de los hogares multigeneracionales y el aumento de los unipersonales, así como por el efecto de las migraciones; la transición a nuevas formas de familias implica una redefinición fundamental de las relaciones de género en toda sociedad, siendo centrales para el diseño de políticas y programas dirigidos hacia la democratización de las familias en la región latinoamericana, las que deben modificar el actual balance entre derechos y obligaciones de hombres y mujeres en el ámbito familiar, se hace énfasis en la incomodidad que no solo a las mujeres sino a los hombres provoca un tipo de modelo rígido de roles, se afirma por tanto que este patrón hegemónico de la masculinidad.

El aumento de la proporción de hogares con jefatura femenina, así como la masiva incorporación de la mujer al mercado laboral, han inducido importantes modificaciones valóricas y de comportamiento en el interior de la familia al flexibilizar los patrones y modelos de las relaciones familiares y de género, fortalecer la autonomía de las mujeres y modificar las identidades masculina y femenina.

La caracterización de las familias en la zona oriental del país, indica que de 2555 familias conformados, el 34,6\% (884) cuentan con jefatura femenina, mientras que el $65,4 \%$ restantes (1671 familias) son familias monoparentales con jefatura masculina (tabla 1).

Tabla 1. Familias por jefatura (masculina, femenina) sin cónyuge y con hijos menores de 18 años en la zona oriental

\begin{tabular}{|c|c|c|c|c|c|c|c|c|c|c|c|c|c|c|}
\hline \multirow{3}{*}{\multicolumn{2}{|c|}{ Regiones y Áreas }} & \multirow{3}{*}{$\begin{array}{c}\text { Total } \\
\text { Familias }\end{array}$} & \multicolumn{4}{|c|}{ Familias por sexo del jefe } & \multirow{2}{*}{\multicolumn{2}{|c|}{$\begin{array}{l}\text { Familia con } \\
\text { jefe mujer } \\
\text { sin cónyuge }\end{array}$}} & \multirow{2}{*}{\multicolumn{2}{|c|}{$\begin{array}{c}\text { Familia con } \\
\text { jefe mujer sin } \\
\text { cónyuge y con } \\
\text { hijos menores } \\
\text { de } 18\end{array}$}} & \multirow{2}{*}{\multicolumn{2}{|c|}{$\begin{array}{l}\text { Familias con } \\
\text { jefe hombre } \\
\text { sin cónyuge }\end{array}$}} & \multirow{2}{*}{\multicolumn{2}{|c|}{$\begin{array}{c}\text { Familias con } \\
\text { jefe hombre } \\
\text { sin cónyuge } \\
\text { y con hijos } \\
\text { menores } \\
\text { de } 18\end{array}$}} \\
\hline & & & \multicolumn{2}{|c|}{ Hombre } & \multicolumn{2}{|c|}{ Mujer } & & & & & & & & \\
\hline & & & Total & $\%$ & Total & $\%$ & Total & $\%$ & Total & $\%$ & Total & $\%$ & Total & $\%$ \\
\hline \multirow[b]{3}{*}{ Oriental } & Total & 2.555 & 1.671 & 65,4 & 884 & 34,6 & 693 & 78,3 & 269 & 38,9 & 373 & 22,3 & 29 & 7,7 \\
\hline & Cabecera & 1.840 & 1.137 & 61,8 & 703 & 38,2 & 559 & 79,5 & 216 & 38,6 & 250 & 22,0 & 18 & 7,2 \\
\hline & $\begin{array}{l}\text { Centros } \\
\text { poblados } \\
\text { y rural } \\
\text { disperso }\end{array}$ & 715 & 533 & 74,6 & 182 & 25,4 & 134 & 73,7 & 53 & 39,8 & 123 & 23,0 & 11 & 8,9 \\
\hline
\end{tabular}

Fuente: elaboración propia con base en Encuesta Nacional de Calidad de Vida, DANE, 2015.

Las familias de la zona oriental ascienden a 2555, se evidencia que $896(35,1 \%)$ son familias con parejas con hijos localizados principalmente en las cabeceras municipales, seguidos de hogares extensos y compuestos con 613 (24\%) familias, 
los hogares unipersonales ascienden a 440 (17,2\%), los hogares monoparentales corresponden a $337(13,2 \%) \mathrm{y}$, finalmente, parejas sin hijos se cuentan 269 hogares $(10,5 \%)$ (tabla 2).

Tabla 2. Tipo de familias en la zona oriental del Colombia en las cabeceras y centros poblados y rural disperso

\begin{tabular}{lcccccc}
\hline $\begin{array}{c}\text { Tipo de } \\
\text { familias }\end{array}$ & Total & \% & Cabecera & \% & $\begin{array}{c}\text { Centros } \\
\text { poblados } \\
\text { y rural } \\
\text { disperso }\end{array}$ & \% \\
\hline $\begin{array}{l}\text { Parejas con } \\
\text { Hijos }\end{array}$ & 896 & 35,1 & 622 & 33,8 & 273 & 38,2 \\
\hline $\begin{array}{l}\text { Hogar } \\
\text { nuclear } \\
\text { monoparental }\end{array}$ & 337 & 13,2 & 267 & 14,5 & 70 & 9,9 \\
\hline $\begin{array}{l}\text { pareja sin } \\
\text { hijos }\end{array}$ & 269 & 10,5 & 181 & 9,9 & 88 & 12,3 \\
\hline $\begin{array}{l}\text { Hogares } \\
\text { unipersonales }\end{array}$ & 440 & 17,2 & 309 & 16,8 & 130 & 18,2 \\
\hline $\begin{array}{l}\text { Extenso y } \\
\text { compuesto }\end{array}$ & 613 & 24,0 & 460 & 25,0 & 153 & 21,4 \\
\hline \multicolumn{1}{c}{ Total } & $\mathbf{2 5 5 5}$ & $\mathbf{1 0 0 , 0}$ & $\mathbf{1 8 4 0}$ & $\mathbf{1 0 0 , 0}$ & $\mathbf{7 1 5}$ & $\mathbf{1 0 0 , 0}$ \\
\hline
\end{tabular}

Fuente: elaboración propia con base en Encuesta Nacional de Calidad de Vida, DANE, 2015.

Las familias en la zona oriental del país estan conformadas en mayor porcentaje por cuatro personas con un $21,9 \%$ sobre el total, familias de tres personas representan el $21,7 \%$ y familias con más de cinco personas son $20,3 \%$ (tabla 3 ).

Tabla 3. Familias por número de personas en la zona oriental de Colombia

\begin{tabular}{|c|c|c|c|c|c|c|c|c|c|c|c|}
\hline \multirow{2}{*}{$\begin{array}{c}\text { Zona } \\
\text { oriental }\end{array}$} & \multirow{2}{*}{$\begin{array}{c}\text { Total } \\
\text { familias }\end{array}$} & \multicolumn{2}{|c|}{ una persona } & \multicolumn{2}{|c|}{ Dos personas } & \multicolumn{2}{|c|}{3 personas } & \multicolumn{2}{|c|}{4 personas } & \multicolumn{2}{|c|}{$\begin{array}{l}5 \text { o más } \\
\text { personas }\end{array}$} \\
\hline & & Total & $\%$ & Total & $\%$ & Total & $\%$ & Total & $\%$ & Total & $\%$ \\
\hline Cabecera & 1840 & 309 & 16,8 & 358 & 19,5 & 424 & 23,0 & 412 & 22,4 & 337 & 18,3 \\
\hline $\begin{array}{l}\text { Centros } \\
\text { poblados y } \\
\text { rural disperso }\end{array}$ & 715 & 130 & 18,2 & 125 & 17,5 & 130 & 18,1 & 147 & 20,6 & 183 & 25,6 \\
\hline Total & 2555 & 440 & 17,2 & 483 & 18,9 & 553 & 21,7 & 559 & 21,9 & 520 & 20,3 \\
\hline
\end{tabular}

Fuente: elaboración propia con base en Encuesta Nacional de Calidad de Vida, DANE, 2015.

Los cambios sociales han llevado a que las mujeres cumplan un papel más visible en las economías y así mismo en el funcionamiento de los hogares; las tasas de efectividad han ascendido cerca de 5\% en América Latina en los últimos años según estudios revelados por la CEPAL (2015), teniendo en cuenta las marcadas diferencias entre los países de la región. 


\section{Aproximaciones teóricas acerca del enfoque de capacidades}

Desarrollando estos enfoques Sen (2000) gira alrededor de las siguientes categorías: capacidades, funcionamientos, derechos y libertad. En la evaluación de los que se establece al nivel de vida y el desarrollo. La contribución de la libertad al desarrollo puede verse de dos maneras distintas: tanto como un fin, tanto como un medio; la libertad es ante todo el fin principal del desarrollo. Es decir, el punto no es aumentar la libertad para lograr otra cosa, sino que es poder aumentar la libertad por la libertad en sí misma. En cuanto a la libertad como medio, Sen sostiene que además de ser el objetivo último del desarrollo, la libertad puede ser una excelente herramienta para lograr el desarrollo.

En cuanto a la privación de la desigualdad entre mujeres y hombres, el enfoque de Sen (2000) concentra el problema a la incapacidad de poder ver a la mujer como un agente activo de cambio, es decir, como promotoras de transformaciones sociales, lo cual se ve reflejado en su bienestar, como por ejemplo la incapacidad para conseguir un trabajo digno y adecuado o tener reconocimiento de sus derechos. Braidotti, R. (1991) plantea que "La visibilización moderna de las mujeres, la participación social ampliada y la propia reivindicación humana, han puesto en crisis el paradigma del mundo patriarcal" pues aunque "las mujeres no tienen los mismos derechos de acceso a la educación, lo que les permitiría mejorar su posición en las escalas social y económica; que de los, aproximadamente, 550 millones de personas trabajadoras pobres del mundo, un $60 \%$ son mujeres, o que las mujeres tenemos unos ingresos de entre un $30 \%$ y un $60 \%$ menor que los hombres" (Allende \& Pepa, s.f. p.5); se requiere una transformación social para lograr la equidad.

Para entender mejor el concepto de capacidades es necesario introducir el concepto de funcionamiento, el cual se refiere a estados de existencia y acciones que una persona consigue o realiza a lo largo de su vida: "las cosas que logra hacer o ser al vivir" (Sen, 2000, p. 55). Entre ellos pueden ser: actividades, como leer o escribir; estados físicos, como estar bien alimentado o sano, evitar enfermedades y muerte prematura; hasta situaciones de más complejidad como ser feliz, participar en la vida de la comunidad, tener dignidad, luchar por el bienestar de los suyos, entre otros.

Para alcanzar estos estados el individuo puede hacer diferentes acciones como por ejemplo, asistir a la escuela, alimentarse, decidir buscar un buen trabajo que le garantice estabilidad económica y personal, entre otros, es decir, el concepto de capacidad representaría todas las mezclas estados y acciones (funcionamientos) que un individuo puede llegar a obtener para alcanzar un cierto nivel de vida.

Ahora bien, Nussbaum (2002) presentó su lista de diez capacidades funcionales humanas centrales, las cuales son: vida, control sobre su propio entorno, otras especies, razón práctica, salud física, afiliación, integridad física, emoción, sentidos, pensamiento e imaginación, y juego. El objetivo de estas es brindar un sentido que 
conlleve hacia los derechos humanos como requisito de dignidad. Según Nussbaum el enfoque de capacidades es universal "la idea es que las capacidades en cuestión son importantes para todos los ciudadanos, en todos los países, y que toda persona debe ser tratada como un fin" (Nussbaum, 2002, p. 90).

\section{Metodología}

La metodología utilizada fue mixta o multimodal, Hernández, Fernández \& Baptista (2012) lo definen como:

El enfoque mixto es un proceso que recolecta, analiza y vincula datos cuantitativos y cualitativos en un mismo estudio una serie de investigaciones para responder a un planteamiento del problema. Se usan métodos de los enfoques cuantitativo y cualitativo y pueden involucrar la conversión de datos cuantitativos en cualitativos y viceversa. Asimismo, el enfoque mixto puede utilizar los dos enfoques para responder distintas preguntas de investigación de un planteamiento del problema. Enfoque mixto puede utilizar los dos enfoques -cuantitativo y cualitativo- para responder distintas preguntas de investigación de un planteamiento del problema (p. 755).

Las técnicas implementadas fueron:

Tabla 4. Técnicas de investigación implementadas

\begin{tabular}{lc}
\hline \multicolumn{1}{c}{ Investigación cuantitativa } & Investigación cualitativa \\
\hline Encuestas & Entrevista en profundidad \\
Estadísticas de fuentes secundarias & Grupo focal
\end{tabular}

Fuente: elaboración propia con base en Hernández, Fernández \& Baptista (2012).

\section{Población}

Según datos del POT en su componente rural (Alcaldía de Villavicencio, 2015), "el municipio de Villavicencio tiene una expansión de 131.126,76 ha, conformadas por $6.201,67$ ha de suelo urbano y de expansión urbana (4,72\% del área total) y 124.925,09 ha de suelo rural $(95,28 \%)$, este último incluye un área suburbana de 10.780 ha $(8,22 \%)$ es decir que tan solo $114.145,09$ ha $(87,06 \%)$ son suelo netamente rural".

El municipio de Villavicencio está dividido administrativamente en el casco urbano y 7 corregimientos que agrupan 58 veredas, el área rural del municipio que cubre el 96\% del territorio, presenta una limitada o reducida presencia de sistemas de producción de economía campesina. Según datos POT, “El 32,63\% del área total del municipio es dedicada a usos agrícolas y un 35,63\% presenta cobertura con pasturas, posiblemente para la actividad pecuaria" (Alcaldía de Villavicencio, 2015). 


\section{Corregimiento No. 7: vereda la Llanerita}

Esta vereda debe su nombre a la hacienda La Llanerita, la cual se dividió en varias fincas, actualmente muchas de estas han sido loteadas para clubes y viviendas campestres. Los primeros habitantes provenían del Viejo Caldas y en menor proporción del departamento del Meta.

Figura 2. Distribución física del corregimiento 7 municipio de Villavicencio, Meta

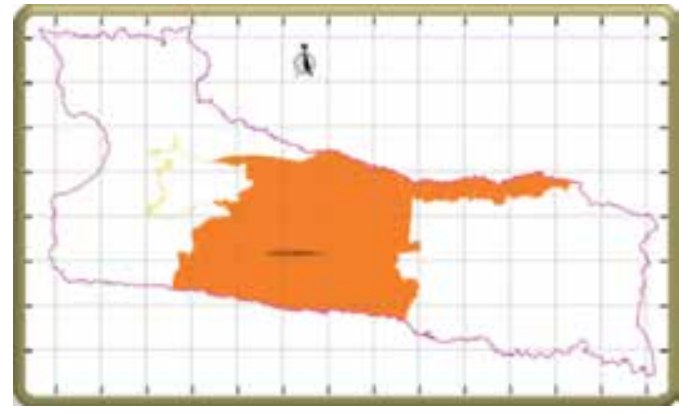

Fuente: Expediente municipal. Diagnóstico sectorial suelo, 2011.

En cuanto a la fisiografía y suelo del corregimiento 7 , en el cual se encuentra la vereda La Llanerita, está ubicado en la zona sur del municipio, en la zona de influencia de los ríos Guayuriba y parte del Ocoa; se caracterizan por tener una topografía plana, formada por aluviones de los ríos; clima cálido con menores precipitaciones que los corregimientos de piedemonte. Según datos del POT Norte, "el $62 \%$ del área se ha establecido en pasturas para la ganadería, gramas, pastos nativos y mejorados. El $25 \%$ del territorio es dedicado a la producción agrícola, particularmente cultivos anuales o semestrales como arroz, soya, maíz, yuca, entre otros" (Alcaldía de Villavicencio, 2015).

Tabla 5. Veredas del corregimiento No.7 del municipio de Villavicencio

\begin{tabular}{rr}
\hline Corregimiento & \multicolumn{1}{c}{ Veredas } \\
\hline & Apiay \\
Barcelona \\
Bella Suiza \\
Canos negros \\
La Llanerita \\
El Cocuy \\
Guamo \\
La Cecilia \\
La Vigia \\
7 \\
San Juan Bosco \\
Santa Helena \\
Vagas del Guayuriba \\
\hline
\end{tabular}

Fuente: elaboración propia con base en POT Norte, componente rural, 2015. 
El corregimiento 7 actualmente tiene el mayor peso porcentual en población rural; las primeras veredas (Apiay, Barcelona, Caños Negros y Cocuy), fueron colonizadas por pobladores originarios de los departamentos de Cundinamarca, Tolima, Santander, Boyacá y del Meta, donde dominaban cultivos de plátano, maíz, yuca, arroz secano y algodón, que fueron reemplazados por pasturas (Alcaldía de Villavicencio, 2015).

\section{Figura 3. Distribución política del corregimiento 7}

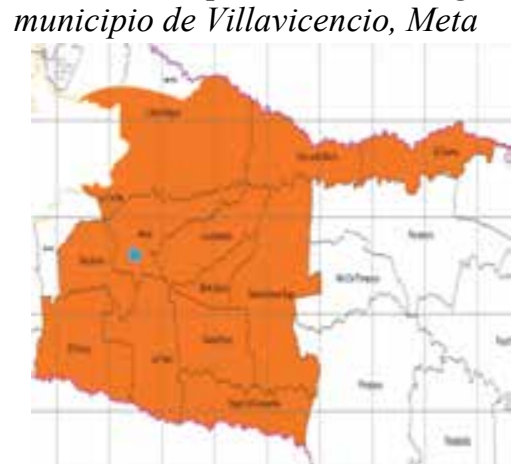

Fuente: Expediente municipal. Diagnóstico sectorial suelo, 2011.

Según datos del POT en su componente rural, en el período 2005 la población de este corregimiento fue de 10.704 habitantes correspondiente al 23,63\% de la población rural, de los cuales el 47\% eran mujeres y el 53\% hombres. Para el 2012 la población fue de 7617 habitantes, es decir, se evidencia una disminución en la población en el corregimiento debido a que por las características topográficas del corregimiento, no ha sido fácil que lleguen nuevos propietarios, porque el corregimiento por mucho tiempo fue afectado por la crisis y los conflictos armados que ha vivido la región.

Tabla 6. Cuadro población por corregimiento Villavicencio, Meta. 2005, 2012 y 2013

\begin{tabular}{ccccccccc}
\hline \multicolumn{7}{c}{ Población por corregimiento } \\
\hline Año & $\mathbf{1}$ & $\mathbf{2}$ & $\mathbf{3}$ & $\mathbf{4}$ & $\mathbf{5}$ & $\mathbf{6}$ & $\mathbf{7}$ & Total \\
\hline 2005 & 7423 & 6352 & 1499 & 16690 & 988 & 1636 & 10704 & 45292 \\
2012 & 4155 & 4890 & 928 & 4510 & 2255 & 613 & 7617 & 24968 \\
2013 & 4297 & 5057 & 960 & 4662 & 2332 & 634 & 7877 & 25819 \\
2014 & 4447 & 5234 & 994 & 4825 & 2414 & 656 & 8152 & 26722 \\
2015 & 4603 & 5417 & 1028 & 4994 & 2498 & 679 & 8438 & 27658 \\
\hline
\end{tabular}

Fuente: POT 2015-Memoria justificativa POT.

La vereda La Llanerita no cuenta con un censo que permita identificar claramente la población que habita en la zona, se cuenta con los siguientes datos. 
Tabla 7. Población de la vereda La Llanerita del municipio de Villavicencio

\begin{tabular}{lc}
\hline \multicolumn{1}{c}{ Población } & Número de personas \\
\hline Hombres & 178 \\
Mujeres & 342 \\
Total & $\mathbf{5 2 0}$ \\
\hline
\end{tabular}

Fuente: Presidenta de la JAC de la vereda La Llanerita, 2016.

\section{Muestra}

A partir de la información suministrada por la presidente de la Junta de Acción Comunal se pudo establecer que en la vereda hay diecinueve mujeres que son jefes de hogar con familias monoparentales.

Tabla 8. Número de mujeres de la vereda La Llanerita del municipio de Villavicencio

\begin{tabular}{lc}
\hline \multicolumn{1}{c}{ Mujeres } & Total \\
\hline Jefes de hogar & 19 \\
No.jefes de hogar & 323 \\
Total & $\mathbf{3 4 2}$ \\
\hline
\end{tabular}

Fuente: Presidenta de la JAC de la vereda La Llanerita, 2016.

\section{Resultados}

Con base en la información mencionada anteriormente, se estimó que la participación de las mujeres jefes de hogar con familias monoparentales para el presente estudio fue:

Tabla 9. Participación de mujeres en las técnicas de recolección

\begin{tabular}{lcc}
\hline \multicolumn{1}{c}{ Técnica } & No. participantes & Porcentaje \\
\hline Encuesta & 11 & $58 \%$ \\
Entrevista en profundidad & 4 & $21 \%$ \\
Grupo focal & 10 & $53 \%$ \\
\hline
\end{tabular}

Fuente: elaboración propia con base en resultados.

Las mujeres que participaron en el grupo focal son las mismas que respondieron la encuesta y a su vez, cuatro mujeres aceptaron hacer la entrevista en profundidad.

Con base en la información recolectada primero se realizó la caracterización socioeconómica de las mujeres jefes de hogar de la vereda La Llanerita, en cuanto a su composición familiar inicial ellas pertenecían a familias nucleares tradicionales, sin evidencia de conflictos intrafamiliares, crecieron en un ambiente rural rodeadas de amistades de la misma edad, no obstante, la escogencia de la pareja fue de hombres 
mayores, algunos con familias previas. Se evidenciaron conflictos entre los padres y sus parejas.

Actualmente las mujeres conformaron sus familias de manera no tradicional, pues no conviven con los padres de sus hijos debido a diferencias culturales como el machismo, crianza, nivel educativo, acceso al trabajo, maltrato, violencia sexual, alcoholismo, decisión sobre número de hijos e infidelidades. El 100\% de las mujeres del presente estudio tienen hijos, la patria potestad de los hijos menores de edad fue asumida por ellas y a su vez estos viven con ellas. El Instituto Colombiano de Bienestar Familiar (ICBF, 2012) menciona en su informe que:

la familia nuclear fue considerada por centurias, como el modelo central de familia. Hoy este predominio en términos cuantitativos es innegable, sin embargo es igualmente cierta, la enorme amplitud y diversidad en la morfología familiar, que se traduce en un espectro amplio de tipologías de familias en Colombia, obedeciendo así mismo, a la amplitud de enfoques, propósitos y preguntas que se hacen quienes la estudian (p. 24).

En el Censo Nacional Agropecuario, realizado por el DANE (2014), estimaron que el 31,9\% de los productores residentes en el área rural dispersa censada las mujeres son los jefes de hogar, los departamentos de mayor proporción fueron el Cauca con $12,6 \%$, seguido de Nariño con 10,4\% y La Guajira con 8,9\%. El departamento del Meta cuenta con una proporción de $1.8 \%$ situándose en el puesto 16 , por encima de Risaralda (1.7\%), Norte de Santander (1.6\%) y Bolívar (1.3\%).

Figura 4. Distribución (\%) del productor residente, jefe de hogar mujer, en el área rural dispersa censada, por departamento

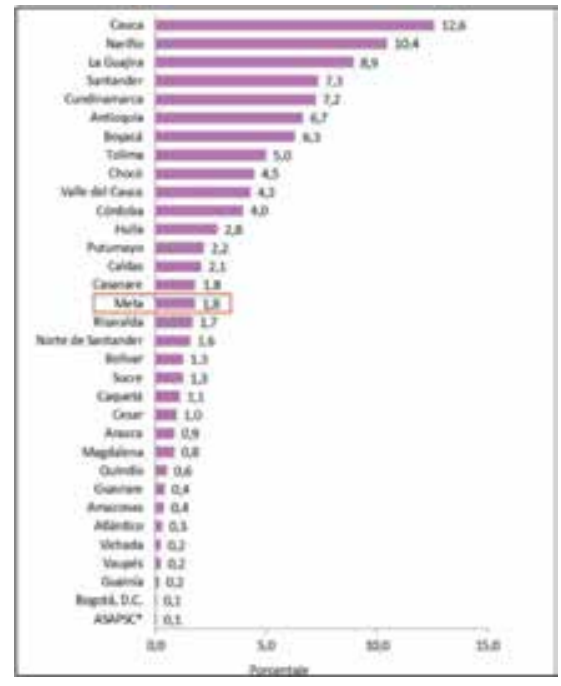

Fuente: DANE-CNA 2014 ASAPSC*: Archipiélago de San Andrés, Providencia y Santa Catalina. 
Con respecto al número de hijos cuatro (4) mujeres indicaron que tienen un (1) hijo, el cual corresponde a un 37\%; cuatro (4) indicaron tener dos (2) hijos, (36\%); tres (3) cuentan con tres (3) hijos, (27\%), y una mujer está embarazada de su primer hijo. Las edades de los hijos oscilan entre 1 año hasta 33 años.

Figura 5. Número de hijos que comprende la familia

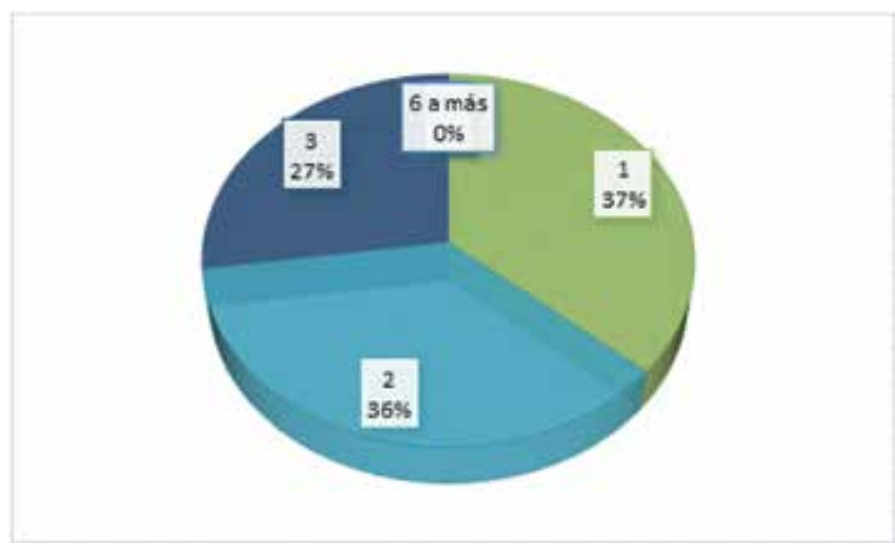

Fuente: resultados de la encuesta 001 implementada en julio de 2016 en la vereda La Llanerita de Villavicencio, Meta.

Las mujeres encuestadas comprenden edades entre 15-25 años (4 mujeres) e igual número de mujeres, edades entre 37-47 años; dos (2) entre 48-59 años, y una sola se encuentra en el rango de edad entre 26-36 años. Se evidencia así, que las mujeres rurales de la vereda en su mayoría son jóvenes con altas expectativas de vida, gozan de buena salud, llevan la mitad de su vida siendo jefe de hogar. La mayoría de ellas tuvieron su primer hijo antes de ser mayores de edad.

Teniendo en cuenta el censo realizado por el DANE (2005), podemos indicar que el aumento de las familias monoparentales con jefatura femenina, se da por la reducción de la base de la pirámide, disminución de menores de 15 años y un aumento en el porcentaje de la población mayor a 40 años, grupos en edad donde estadísticamente se ubican las personas que son jefes de hogar.

Se pudo observar que las mujeres a muy temprana edad asumieron actividades propias de las mujeres adultas y bajo roles estereotipados correspondientes a los desempeñados por el modelo patriarcal. Embarazos en la adolescencia, deserción escolar, desigualdad e inequidad en el desarrollo de actividades domésticas entre otros problemas, esto como consecuencia a sus vivencias. Así lo relata una de ellas:

"yo tenía 14 años cuando quede en embarazo y el papá del hijo mío me llevaba 12 años en ese momento, claro que todavía me los lleva porque no lo he alcanzado 
(risas), y el hombre me decía, yo estaba haciendo noveno grado cuando quede en embarazo, terminé noveno muy bonito, el niño no había nacido, cuando nació me dijo "que si quería estudiar ¿pa que se dejó preñar?”, o sea el que me preño fue él no fue porque yo quise, él era mayor que yo, él me hubiera educado a mí, pero me tocó educarme a mí misma y educarlo a él porque me toco afinarlo entonces (risas) (Grupo Focal, Mujer No.4).

El nivel de escolaridad está distribuido de la siguiente manera: seis (6) mujeres son bachilleres y tres (3) son técnicas, una (1) es tecnóloga y ninguna es profesional. Las mujeres de menos de 30 años tuvieron la oportunidad de culminar su bachillerato en un colegio público y en la edad correspondiente, mientras las mujeres mayores de 30 años, debieron validar para culminar sus estudios, esto se evidencia en la figura 6.

La oferta educativa en la que ellas pueden acceder no cumple con sus expectativas, por lo que realizan estudios en disciplinas alternas a lo que desean. Lo anteriormente dicho, corrobora lo que plantea las Naciones Unidas (1993)

Los derechos humanos de la mujer y de la niña son parte inalienable, integrante e indivisible de los derechos humanos universales. La plena participación, en condiciones de igualdad, de la mujer en la vida política, civil, económica, social y cultural en los planos nacional, regional e internacional y la erradicación de todas las formas de discriminación basadas en el sexo son objetivos prioritarios de la comunidad internacional.

Figura 6. Nivel de escolaridad

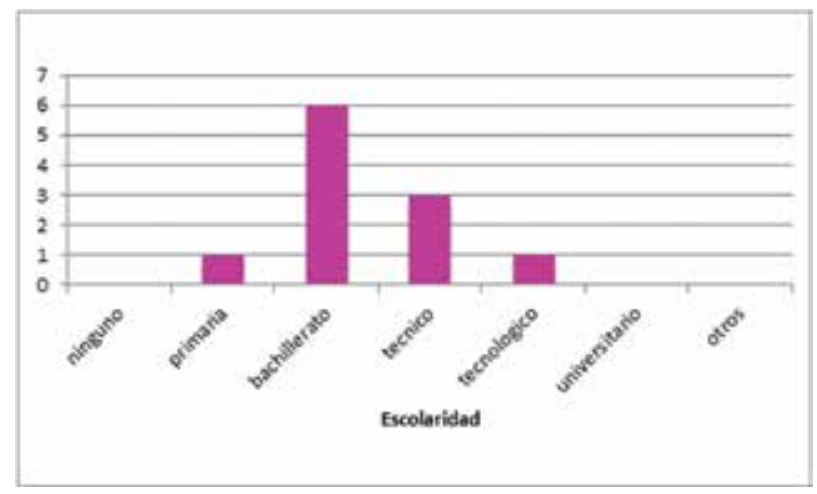

Fuente: resultados de la encuesta 001 implementada en julio de 2016 en la vereda La Llanerita de Villavicencio, Meta.

Teniendo en cuenta que el salario (SMLV) para el 2016 es de $\$ 689.454$, ocho (8) mujeres refirieron que: mensualmente tiene ingresos menores a $\$ 350.000$, dos (2) mujeres obtienen ingresos entre $\$ 700.001-\$ 1.500 .000$, y una con ingresos entre $\$ 350.001-\$ 700.000$; estos resultados se observan en la figura 7. Por lo anterior, 
podemos decir que la mayoría de las mujeres no reciben ni un salario mínimo mensual, los miembros de su familia son altamente dependientes, no cuentan con algún tipo de subsidio del Estado, los ingresos que perciben no alcanzan a cubrir gastos ni costos, por lo cual deben incurrir en préstamos informales con altas tasas de interés, se evidencia también el uso del trueque como medio de subsistencia y de esta manera manifiestan que no se sienten a gusto con sus ingresos.

Adicional a lo antes mencionado, ellas no pueden acceder a mayores ingresos, ya que no cuentan con suficiente tiempo para realizar jornadas laborales completas, porque no hay quien cuide sus hijos.

Echeverri (1994) destaca que:

cualquier estudio social actual muestra que la mitad de la fuerza laboral actual es femenina y que la mayoría de estas mujeres son madres. Se espera que las mujeres no tengan que escoger entre ser esposas y madres, o subsistir, tener independencia económica y tener éxito laboral; pero que tampoco se tengan que conformar con cumplir con todos los roles simultáneamente, a costa de su salud física y mental (p. 119).

Figura 7. Ingreso mensual

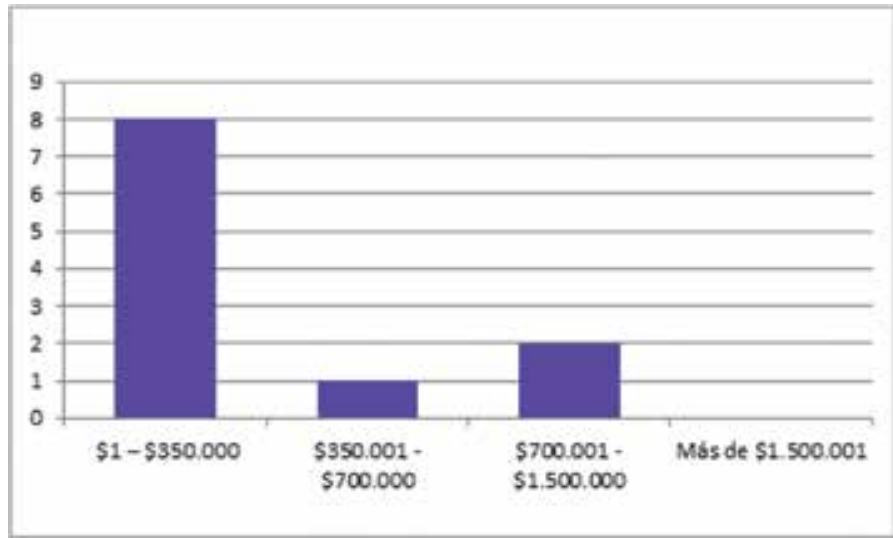

Fuente: resultados de la encuesta 001 implementada en julio de 2016 en la vereda La Llanerita de Villavicencio, Meta.

La situación económica se especifica en estos dos relatos:

“...Siempre que para el mercado no tengo, porque entonces ya no alcanza el mercado sino que toca liviadito, liviadito, bregando ahí para comprar (Entrevista, mujer No.1).

Las actividades económicas a las que se dedican son variadas, seis mujeres afirmaron que son empleadas en actividades como en panaderías, doméstica, guardas 
de seguridad; cuatro (4) desempleadas dedicadas al hogar y una (1) es independiente con una caseta de gaseosas.

El hecho de que los ingresos totales del hogar dependan principalmente de la remuneración que una mujer pueda obtener por su trabajo significa, en promedio, que ese hogar tendrá menores ingresos que aquellos de los que puede disponer una familia que depende del trabajo de un hombre, puesto que, en promedio, los ingresos que percibe una principal perceptora mujer son menores que los que percibe un principal perceptor varón que trabaja la misma cantidad de horas (Geldstein, 1994).

A ello se añade el hecho de que si la jefa tiene a su cargo hijos de corta edad y no puede disponer de la ayuda solidaria o remunerada de otro adulto, los niños se convierten en un factor que disminuye el tiempo posible de dedicación laboral de la madre, disminuyendo también el nivel de ingresos que ella puede obtener en el mercado (Geldstein, 1997).

Las mujeres indican que lo más difícil es la imposibilidad de trabajar, porque no hay quien cuide a los hijos, los empleadores no cumplen con los pagos ni prestaciones sociales, falta de apoyo económico, la cuota que paga el padre de los hijos no solventa todos los gastos que requieren, las escasas oportunidades laborales, ser papá y mamá al mismo tiempo, rechazo al padre, miedo a que los hijos no se realicen como personas y dejar solos a los hijos largos períodos de tiempo mientras se va a trabajar son sus mayores dificultades.

...la idea mía, yo quiero es estar trabajando no quiero ser una carga desde ya para mis hijos, yo me siento capacitada para seguir trabajando y por ejemplo a mí me salen dos o tres días o que me salga, la idea es ponerme a trabajar fija o poner un negocio... (Entrevista, mujer No.7).

Se tomaron las diez capacidades propuestas por Nussbaum (2002) desde un enfoque de las amarguras a las que se enfrentan las mujeres en países en vía de desarrollo y se implementaron una serie de indicadores, los cuales permitieron comprender el contexto y las dificultadas que afrontan las mujeres de la vereda La Llanerita. A continuación, se presentan las capacidades con su descripción:

Tabla 10. Diez capacidades humanas básicas y su descripción

\begin{tabular}{|c|c|c|}
\hline Capacidad básica & Descripción & Interpretación \\
\hline Vida & $\begin{array}{l}\text { Poder vivir hasta el término de una vida } \\
\text { humana de una duración normal; no morir } \\
\text { de forma prematura o antes de que la propia } \\
\text { vida se vea tan reducida que no merezca la } \\
\text { pena vivirla. }\end{array}$ & $\begin{array}{l}\text { Esta capacidad hace referencia a la expectativa de vida que } \\
\text { una persona tiene. De poder desarrollar sus capacidades y } \\
\text { ejercer sus libertades con respecto a tener la vida que desea. } \\
\text { Es decir, disponer de las mismas oportunidades que los } \\
\text { demás. No tener la preocupación por la falta de alimentos. } \\
\text { Una política de equidad de género debe garantizar no solo } \\
\text { tratar de erradicar la discriminación como un ejercicio de } \\
\text { los derechos de las mujeres, sino una base de igualdad entre } \\
\text { mujeres y hombres que permita el desarrollo de una vida } \\
\text { digna en todos los aspectos. }\end{array}$ \\
\hline
\end{tabular}




\begin{tabular}{|c|c|c|}
\hline Capacidad básica & Descripción & Interpretación \\
\hline Salud física & $\begin{array}{l}\text { Poder mantener una buena salud, incluida } \\
\text { la salud reproductiva; recibir una } \\
\text { alimentación adecuada; disponer de un } \\
\text { lugar adecuado para vivir. }\end{array}$ & $\begin{array}{l}\text { Se enfoca en las condiciones del individuo, el acceso a los } \\
\text { servicios de salud, los cuidados nutricionales. Tener la } \\
\text { oportunidad de otorgarle a su cuerpo una buena salud con el } \\
\text { fin de no desarrollar enfermedades. } \\
\text { En términos de equidad de género es importante la libertad } \\
\text { personal y el reconocimiento, tratando a cada ser como un } \\
\text { fin no como un medio. Que cada ser puede decidir sobre su } \\
\text { sexualidad, que pueda elegir. De manera que la equidad de } \\
\text { género contribuya a la promoción de una salud preventiva. }\end{array}$ \\
\hline
\end{tabular}

a. Poder vivir con y para los otros, reconocer y mostrar preocupación por otros seres humanos, participar en diversas formas de interacción social; ser capaz de imaginar la situación de otro. (Proteger esta capacidad implica proteger las instituciones que constituyen y promueven estas formas de afiliación, así como proteger la libertad de expresión y de asociación política)

b. Bases sociales del autorespeto y la no humillación; ser tratado como un ser dotado de dignidad e igual valor que los demás. Eso implica introducir disposiciones contrarias a la discriminación por razón de raza, sexo, orientación sexual, etnia, casta, religión y origen nacional.

Esta capacidad lleva al desarrollo de las relaciones afectivas entre la sociedad, partiendo de la igualdad y el reconocimiento del otro, llegando al cuidado individual; su ser, su cuerpo, su mente.

En este caso, ese reconocimiento del otro se debe a la igualdad entre hombres y mujeres, de la aceptación y el cuidado mutuo. Una vez se logre este reconocimiento se dará paso a interacciones con otras personas, a esa afiliación que permitirá lograr objetivos comunes y mejoras en su situación particular.

Una política de equidad de género debe propender por el autorespeto, en cuanto garantiza un bienestar físico y emocional, así como por el respeto a los otros en la medida en que se permite el reconocimiento mutuo.

Esta capacidad hace énfasis a que las personas a través de sus capacidades y libertades, tengan la oportunidad de preocuparse por el prójimo, de razonar y dar soluciones ante los problemas que abarcan las vidas de otros, como es el caso de la falta de equidad de género, la falta de reconocimiento hacia el otro, generando un ambiente de desigualdad. mismos; poder amar a aquellos que nos aman y se preocupan por nosotros, y dolernos por su ausencia; en general, poder amar, penar, experimentar ansia, gratitud y enfado justificado. Que nuestro desarrollo emocional no quede bloqueado por el miedo y la ansiedad. (Defender esta capacidad supone defender formas de asociación humana de importancia crucial y demostrable para este desarrollo).

Este ambiente de desigualdad en el caso de las mujeres, genera una serie de obstáculos para el ascenso social, lo que termina en el deterioro de las condiciones emocionales, quienes en últimas ven el ejercicio de sus capacidades y la consecución de una buena forma de vida como un imposible, generando sentimientos de inferioridad, pesimismo y exclusión.

Una política de equidad de género debe centrarse en tales vulnerabilidades y desigualdades, promoviendo una mejora en las emociones, incluyendo leyes que abarquen la familia, violación, seguridad pública como lo menciona Nussbaum.

a. Político. Poder participar de forma efectiva en las elecciones políticas que gobiernan la propia vida; tener derecho a la participación política y a la protección de la libertad de expresión y de asociación. b. Material. Poder disponer de propiedades (ya sean bienes mobiliarios o

Control sobre su propio entorno inmobiliarios), y ostentar los derechos de propiedad en un plano de igualdad con los demás; tener derecho a buscar trabajo en un plano de igualdad con los demás; no sufrir persecuciones y detenciones sin garantías. En el trabajo, poder trabajar como un ser humano, ejercer la razón práctica y entrar en relaciones valiosas de reconocimiento mutuo con los demás trabajadores.
Esta capacidad se enfoca en la importancia que representa para todas las personas el acceso los servicios, y ese acceso está determinado por el consumo, es decir por medio de sus recursos económicos.

En términos de equidad de género el control sobre el entorno material supera al control sobre el entorno político, ya que es a través de este que se promueve de manera individual el ejercicio de las capacidades humanas. Es decir, solo un sistema político que tenga como base el reconocimiento de las personas podrá garantizar, en gran parte, la equidad. 


\begin{tabular}{|c|c|c|}
\hline Capacidad básica & Descripción & Interpretación \\
\hline Integridad física & $\begin{array}{l}\text { Poder moverse libremente de un lugar a } \\
\text { otro; estar protegido de los asaltos violentos, } \\
\text { incluidos los asaltos sexuales y la violencia } \\
\text { doméstica; disponer de oportunidades para } \\
\text { la satisfacción sexual y para la elección en } \\
\text { cuestiones reproductivas. }\end{array}$ & $\begin{array}{l}\text { Esta capacidad es de suma importancia, haciendo énfasis } \\
\text { en la inseguridad que muchas veces pasan las mujeres en } \\
\text { sus entornos, por ende es importante resaltar los derechos } \\
\text { humanos de las personas a poder vivir y pensar libremente. } \\
\text { De no tener la preocupación de vivir con miedo y poder } \\
\text { garantizar el pleno desarrollo físico, lo que incluye la salud y } \\
\text { el ejercicio de todas las funciones vitales. } \\
\text { Por tanto, implica el cumplimiento de los derechos humanos } \\
\text { (derechos económicos, sociales, culturales y ambientales) y } \\
\text { de los derechos sexuales y reproductivos. }\end{array}$ \\
\hline Razón práctica & $\begin{array}{l}\text { Ser capaz de plasmar una concepción del bien } \\
\text { y de comprometerse en una reflexión crítica } \\
\text { acerca del planeamiento de la propia vida. }\end{array}$ & $\begin{array}{l}\text { Implica la capacidad de elaborar una concepción del bien, de } \\
\text { lo que es correcto en la vida individual y colectiva y de asumir } \\
\text { con capacidad crítica la vida propia. }\end{array}$ \\
\hline $\begin{array}{l}\text { Sentidos, } \\
\text { imaginación y } \\
\text { pensamiento }\end{array}$ & $\begin{array}{l}\text { Poder utilizar los sentidos, imaginar, } \\
\text { pensar y razonar. A partir de una buena } \\
\text { educación. Poder utilizar la imaginación } \\
\text { y el pensamiento en conexión con la } \\
\text { experiencia y la producción de obras y } \\
\text { eventos de elección propia, en lo religioso, } \\
\text { literario, musical, entre otros. Utilizar } \\
\text { su propia mente de manera protegida por } \\
\text { las garantías de libertad de expresión con } \\
\text { respeto, tanto al discurso político como } \\
\text { artístico y libertad religiosa. Ser capaz de } \\
\text { tener el sentido último de la vida a la propia } \\
\text { manera. Ser capaz de tener experiencias } \\
\text { placenteras de evitar el sufrimiento } \\
\text { innecesario. }\end{array}$ & $\begin{array}{l}\text { Hace referencia a poder expresar nuestra libertad por medio } \\
\text { de nuestros sentidos, pensamiento e imaginación. Esto } \\
\text { con base en ser libres y educados realizando elecciones no } \\
\text { afectadas por una baja autoestima. }\end{array}$ \\
\hline Otras especies & $\begin{array}{l}\text { Ser capaz de vivir y cuidar a los animales, } \\
\text { las plantas y el mundo de la naturaleza y en } \\
\text { relación con todo ello. }\end{array}$ & $\begin{array}{l}\text { Se trata en un sentido más amplio de poder lograr una relación } \\
\text { de cuidado por la naturaleza, haciendo referencia a los } \\
\text { fenómenos del mundo físico y también a la vida en general. }\end{array}$ \\
\hline Juego & $\begin{array}{l}\text { Poder disfrutar de la vida, de los momentos, } \\
\text { de poder reír, jugar. }\end{array}$ & $\begin{array}{l}\text { Hace referencia a que todas las personas puedan disfrutar de } \\
\text { la vida en todo su esplendor, en el caso de las mujeres que } \\
\text { son cabeza de hogar que puedan tener tiempo para mejorar } \\
\text { su calidad de vida. }\end{array}$ \\
\hline
\end{tabular}

Fuente: elaboración propia con base en Nussbaum (2002).

\section{Los resultados obtenidos fueron:}

\section{Vida}

Los proyectos de vida se pueden llevar a cabo, pero a las mujeres les toca postergarlos así no sean cabeza de hogar, no obstante, la tenacidad, la perseverancia y el proyectar un futuro mejor para sus hijos son la motivación y los medios que se tienen para realizar lo planeado.

Ocho mujeres indicaron que tuvieron sus hijos por parto natural y tres por cesárea. Esto indica que las mujeres tienen acceso a centros de salud y hospitalarios, no obstante, se evidenció un caso en el que por negligencia médica, la mujer sufrió un aborto espontaneó producto de la ingesta de un medicamento sin saber que estaba en estado de embarazo, conllevándola así a estados de depresión y tristeza; el cual fue superado tiempo después mediante terapias y ayuda psicológica. 
En cuanto a cotización a seguridad social siete (7) mujeres de las once (11) encuestadas están afiliadas a una EPS, esto refleja que, en el transcurso de sus vidas, sí han tenido trabajos estables, pero los han tenido que dejar por las circunstancias.

Figura 8. Cotización a seguridad social

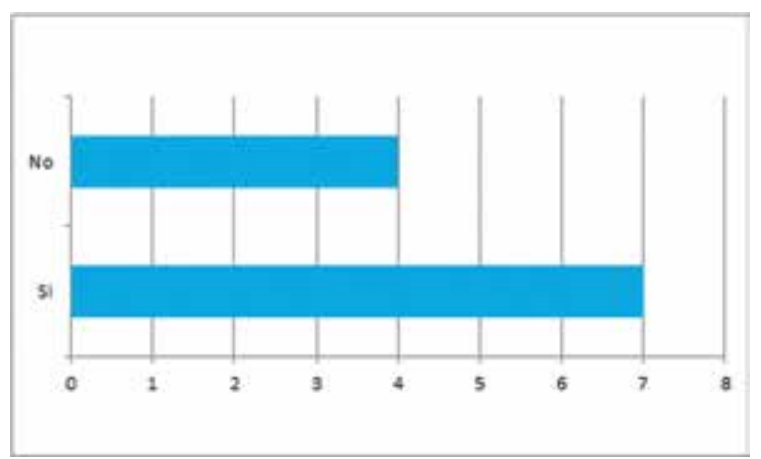

Fuente: resultados de la encuesta 001 implementada en julio de 2016 en la vereda La Llanerita de Villavicencio, Meta.

Arriagada (2001) considera que los empleos obtenidos por las mujeres son de mala calidad, de carácter cíclico y tienen el riesgo de competir con los de otros miembros del hogar, observa que la mayor participación femenina en América Latina incluye a las mujeres menos educadas y que se ha ido independizando de los ciclos económicos, por lo que se considera parte de un proceso cultural relacionado con su mayor autonomía y participación en todos los ámbitos sociales.

Con los resultados obtenidos, se concluye que las mujeres rurales de la vereda La Llanerita, tienen una capacidad de poder vivir hasta el término de una vida humana de una duración normal; no morir de forma prematura o antes de que la propia vida se vea tan reducida que no merezca la pena vivirla. De:

Tabla 11. Resultado de la capacidad Vida

\begin{tabular}{|c|c|c|c|}
\hline Capacidad Básica & Indicador & Formula & Resultado \\
\hline \multirow{2}{*}{ Vida } & $\begin{array}{l}\% \text { de mujeres rurales } \\
\text { con jefatura femenina de } \\
\text { familias monoparentales } \\
\text { que cotizan seguridad } \\
\text { social }\end{array}$ & 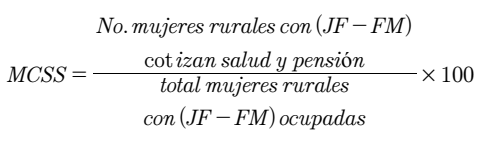 & $18 \%$ \\
\hline & $\begin{array}{c}\text { Tasa de mortalidad en } \\
\text { mujeres rurales con } \\
\text { jefatura femenina de } \\
\text { familias monoparentales } \\
\text { por causas }\end{array}$ & 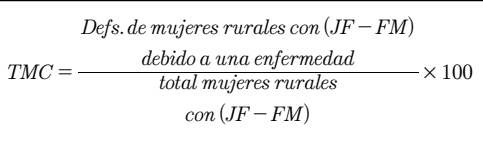 & $\begin{array}{c}\text { No } \\
\text { encontrado }\end{array}$ \\
\hline
\end{tabular}

Fuente: resultados de la encuesta 001 implementada en julio de 2016 en la vereda La Llanerita de Villavicencio, Meta. 


\section{Salud física}

Aunque seis de las mujeres encuestadas han asistido a programas de salud sexual y reproductiva (figura 9), los inicios sexuales no estuvieron marcados por la información adquirida dentro de sus familias, sino por terceros, como el señor de la droguería, amigos, profesores. Las decisiones tomadas sobre sus cuerpos han sido propias y autónomas. Las mujeres que indicaron ser sexualmente activas, planifican con algún método anticonceptivo diagnosticado por el médico.

Además, es importante tener presente que como ellas son las responsables de su familia, asumieron el rol activo de enseñarle a sus hijos cómo llevar la sexualidad evitando embarazos y enfermedades de transmisión sexual, siempre inculcando los valores como eje central de la formación. La mayoría de las mujeres decidieron ligarse las trompas de Falopio para evitar más embarazos, aún en contra de sus parejas.

Figura 9. Asistencia a programas de salud sexual y reproductiva

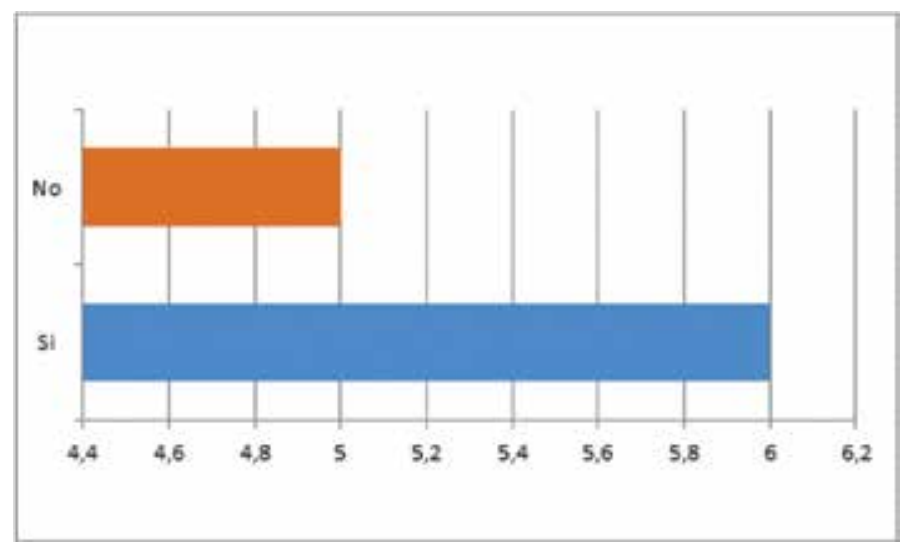

Fuente: resultados de la encuesta 001 implementada en el julio de 2016 en la vereda La Llanerita de Villavicencio, Meta.

Lo anterior es producto de:

la búsqueda de reconocimiento que ha sido la oposición a la desigualdad y al androcentrismo cultural definido como la visión del mundo que sitúa al hombre como centro de todas las cosas. A mediados de la década de los años 80 el debate cambio, y se centró en las "diferencias entre mujeres (Fraser, 1997, p. 236).

La educación sexual de las mujeres de la vereda se define en estos relatos:

Yo inicié mi vida sexual a los 14 años, vulgarmente aquí ya somos grandes todas "apenas lo probé, quedé en embarazo" (risas), inmediatamente, no pasaron ni 20 días y ya estaba cuajada (risas)...” (Grupo Focal, Mujer No.4). 
“...yo fui a una droguería, yo le pregunté al de la droguería, yo con mucha pena y todo, le dije "hágame un favor ¿cómo hago para planificar que yo no quiero tener hijos?" el señor de la droguería me dijo "itiene tiempo?” yo le dije "si señor", ese señor llegó y se sentó en una panadería y sacó y me explicó..." (Grupo Focal, Mujer No. 1).

Con los resultados obtenidos, se concluye que las mujeres rurales de la vereda La Llanerita, tienen una capacidad de salud física:

Tabla 12. Resultado de la capacidad Salud física

\begin{tabular}{|c|c|c|c|}
\hline Capacidad Básica & Indicador & Formula & Resultado \\
\hline \multirow{2}{*}{ Salud física } & $\begin{array}{l}\% \text { de mujeres rurales } \\
\text { con jefatura femenina de } \\
\text { familias monoparentales } \\
\text { con acceso a programas } \\
\text { de salud sexual y } \\
\text { reproductiva }\end{array}$ & 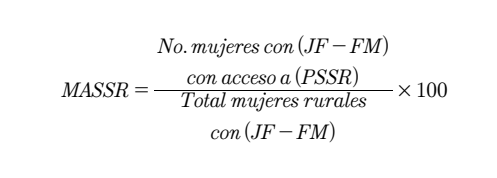 & $55 \%$ \\
\hline & $\begin{array}{c}\% \text { de mujeres rurales } \\
\text { con jefatura femenina de } \\
\text { familias monoparentales } \\
\text { que cotizan seguridad } \\
\text { social }\end{array}$ & 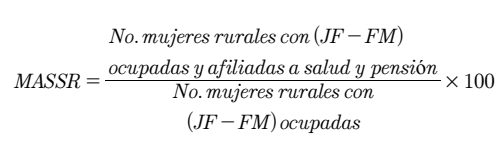 & $18 \%$ \\
\hline
\end{tabular}

Fuente: resultados de la encuesta 001 implementada en julio de 2016 en la vereda La Llanerita de Villavicencio, Meta.

\section{Afiliación}

Para ellas el significado de afiliación es el amor, es tener una criatura en su vientre y saber que lo va a ser todo en la vida, y que se va a dar lo mejor para él, "no el que le pinta pajaritos en el aire". El amor es esperanza, un sentimiento, una fortaleza que hay en una relación y algo que se debe cultivar. En cuanto a tener pareja se encuentra que hay posturas que se alejan en el discurso, pues cada una tiene una interpretación distinta de la misma, mientras unas plantean la necesidad de tener un apoyo, compañía y un ser que las ame, otras, por el contrario, afirman no necesitarlo y son felices así.

Las mujeres que pertenecen a alguna organización gremial o comunitaria, son cuatro (4), el resto no han tenido la oportunidad ni el tiempo para ello, o la vereda no cuenta con organizaciones gremiales para pertenecer. Ahora bien, ellas les gustaría crear una organización que se adecue a sus necesidades y que puedan verse reconocidas en ella (figura 10). 
Figura 10. Pertenece a organizaciones gremiales o comunitarias

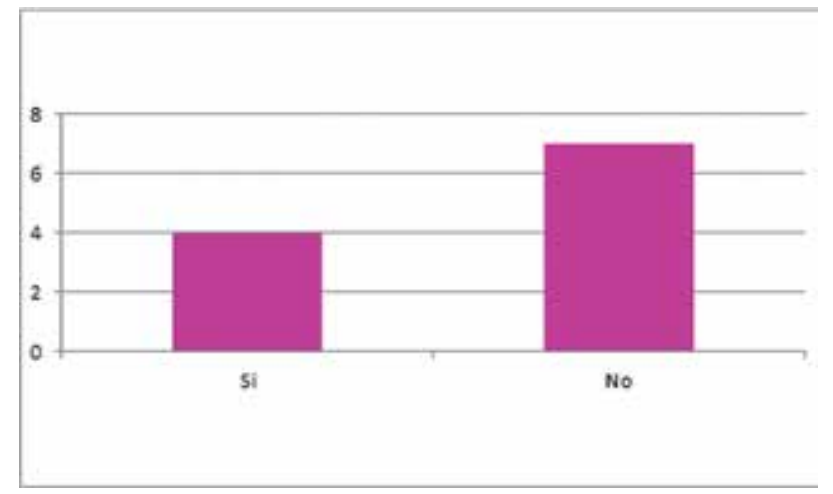

Fuente: resultados de la encuesta 001 implementada en julio de 2016 en la vereda La Llanerita de Villavicencio, Meta.

En este sentido Fraser (1997) propone debatir los temas de igualdad social y la diferencia cultural, desarrollar visiones multiculturales de la pluralidad y combinar la lucha por el multiculturalismo antiesencialista con la lucha por la igualdad social, en la que el acceso a las oportunidades sea equitativo y genere la ampliación de capacidades de cada una de ellas.

Adicional a esto, tan solo dos mujeres cotizan actualmente seguridad social. Según Álvarez (s.f.), aunque se ha incrementado la participación de las mujeres en las actividades económicas, se evidencia que la calidad de los empleos es precaria y se mantiene una gran brecha con los ingresos de los hombres. Además, tres cuartas partes del total de mujeres rurales en Colombia se encuentran en condición de pobreza; al carecer de cotizaciones en seguridad social las desprotege tanto en el presente como en el futuro ante accidentes laborales y al derecho de una jubilación cuando no puedan trabajar más.

En la caracterización que el DANE (2016) presentó del Censo Nacional Agropecuario evidencia que:

Los jefes de hogar de Villavicencio son 527.847 personas que corresponden al $72,8 \%$ de la población rural, de la cual el $23,4 \%$ son mujeres y $76,6 \%$ son hombres. De estos el 56,8\% cuentan con estudios hasta basica primaria, el $20,1 \%$ no cuenta con ningun tipo de estudios, el $9,5 \%$ tiene estudios hasta secundaria. En cuanto estudios universitarios, el 1,6\% indico contar con ellos de los cuales el $25 \%$ (2.136) corresponde a mujeres y el $75 \%(6.410)$ a hombres. 
Figura 11. Actualmente cotiza a seguridad social

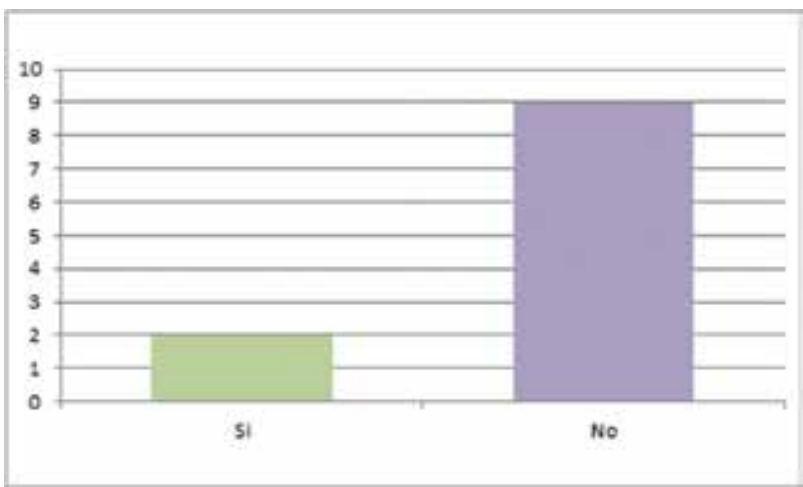

Fuente: resultados de la encuesta 001 implementada en julio de 2016 en la vereda La Llanerita de Villavicencio, Meta.

En consecuencia del bajo nivel de escolaridad y las pocas oportunidades laborales que hay en la zona, las mujeres de la vereda la Llanerita posiblemente no puedan acceder a la pensión cuando cumplan la edad, obligándolas así a trabajar durante toda su vida para subsistir y en algunos casos sobrevivir.

Algunos programas llegan a la vereda con el fin de mejorar sus capacidades y habilidades, no obstante se evidencia alta inasistencia a los mismos:

La conclusión que me queda es que ya somos diez mujeres, porque a veces llegan programas bonitos a la vereda, pero no vamos y entonces a mí me habían dicho que eran dieciocho y ¿dónde están? Es que llegan programas, pero la gente no va (Grupo Focal, Mujer No.4).

Los resultados obtenidos demuestran que las mujeres rurales de la vereda $\mathrm{La}$ Llanerita tienen una capacidad de afiliación:

Tabla 13. Resultado de la capacidad Afiliación

\begin{tabular}{cccc}
\hline Capacidad Básica & Indicador & Formula & Resultado \\
\hline & \% de mujeres & & \\
& rurales con jefatura & & \\
femenina de familias & No. mujeres rurales con $(J F-F M)$ & \\
monoparentales que & $M I O=\frac{\text { integran organizaciones gremiales }}{\text { total mujeres rurales }} \times 100$ & $36 \%$ \\
& integran organizaciones & con $(J F-F M)$ & \\
& gremiales o & & \\
& comunitarias & &
\end{tabular}

Fuente: resultados de la encuesta 001 implementada en julio de 2016 en la vereda La Llanerita de Villavicencio, Meta. 


\section{Emociones}

En esta capacidad Nussbaum (2000) hace énfasis en que las personas a través de sus capacidades y libertades, tienen la oportunidad de preocuparse por el prójimo, de razonar y dar soluciones a los problemas que abarcan las vidas de otros, como la inequidad de género, la falta de reconocimiento hacia el otro, generando para todos ambientes mas favorables.

Es por ello que para determinar esta capacidad se midió el contacto con los padres de los hijos, a lo cual seis (6) afirman mantenerlo y cinco (5) no mantienen contacto con ellos (figura 12). Se indago sobre el tipo de relación que tenían y ellas indicaron que la relación era tan solo económica, es decir, que tan solo es por cuestiones monetarias como el pago de la cuota de alimentos. No obstante, manifestaron la importancia de la presencia del padre en cuanto a la crianza de los hijos, más como una figura de autoridad.

Figura 12. Contacto o relación con el padre de los hijos

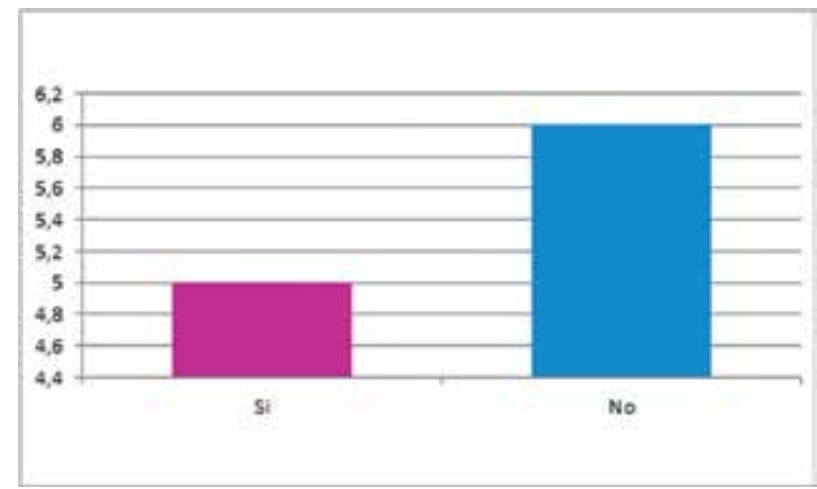

Fuente: resultados de la encuesta 001 implementada en julio de 2016 en la vereda La Llanerita de Villavicencio, Meta.

La expectativa de vida es tener una casa propia, continuar con estudios superiores, conseguir un mejor empleo, o un empleo, mejorar sus ingresos, contar con ayuda estatal para el desarrollo de proyectos en la vereda. La propuesta que plantean las mujeres son programas para la comunidad que las beneficien, y trabajo para las madres cabezas de familia, que permitan entonces visibilizar las vereda como lugar de turismo y recreación en el que genere empleo y mejores condiciones de trabajo.

Es importante mencionar que la información de programas de autoestima, estrés, depresión no existe, ya que el Gobierno local no ha realizado este tipo de actividades en la vereda La Llanerita. 
Las emociones para las mujeres están ligadas profundamente con sus hijos y su familia, así lo expresa:

que más amor y que más querer que tener una criatura, crecer y saber que lo va a ser todo en la vida, y que uno va a dar lo mejor para él, para mí eso es verdadero amor, no el que le pinta pajaritos en el aire que "sí que mi amor yo la amo, vamos hasta el fin del mundo" que una cosa y la otra no, el amor bonito y para el amor bonito es un hijo es cuando nace (Grupo Focal, Mujer No. 6).

La capacidad de emociones de las mujeres rurales jefes de hogar de la vereda La Llanerita es:

Tabla 14. Resultado de la capacidad Emociones

\begin{tabular}{cccc}
\hline Capacidad Básica & Indicador & Formula & Resultado \\
\hline \multirow{5}{*}{ Emociones } & $\begin{array}{c}\text { No. de programas de } \\
\text { autoestima, manejo } \\
\text { de estrés, manejo de } \\
\text { depresión en mujeres } \\
\text { rurales de familias } \\
\text { monoparentales }\end{array}$ & $\begin{array}{c}\text { Programa de autoestima, manejo de estrés, } \\
\text { depresión a los que han asistido las mujeres } \\
\text { rurales (JF-FM) en los últimos tres (3) años }\end{array}$ & No encontrado \\
\cline { 2 - 4 } & $\begin{array}{c}\text { \% de mujeres } \\
\text { rurales con jefatura } \\
\text { femenina de familias } \\
\text { monoparentales que } \\
\text { integran organizaciones } \\
\text { gremiales o } \\
\text { comunitarias }\end{array}$ & MIO $=\frac{\text { No.mujeres rurales con }(\mathrm{JF}-\mathrm{FM})}{\text { Integ.organizaciones }}$ & total mujeres rurales \\
con $(\mathrm{JF}-\mathrm{FM})$ & & $36 \%$ \\
\hline
\end{tabular}

Fuente: resultados de la encuesta 001 implementada en julio de 2016 en la vereda La Llanerita de Villavicencio, Meta.

\section{Integridad física}

Esta capacidad es de suma importancia, hace énfasis en la inseguridad que muchas veces pasan las mujeres en sus entornos, por ende, es importante resaltar los derechos humanos de las personas a poder vivir y pensar libremente. De no tener la preocupación de vivir con miedo y poder garantizar el pleno desarrollo físico, lo que incluye la salud y el ejercicio de todas las funciones vitales.

Han cotizado a seguridad social siete (7) mujeres de las once (11) encuestadas y seis han asistido a programas de salud sexual y reproductiva.

La vereda es un lugar tranquilo y posibilita la crianza de sus hijos:

En el caso de esta vereda a comparación de Villavicencio, uno vive en mucha tranquilidad, porque por mucho conflicto que vea fue que el vecino se agarró con la vecina y ya, pero en caso de orden público uno cuenta con la seguridad de la policía y la fuerza aérea (Grupo Focal, Mujer No. 1). 
La capacidad de integridad física de las mujeres rurales jefes de hogar de la vereda La Llanerita es:

Tabla 15. Resultado de la capacidad Integridad física

\begin{tabular}{|c|c|c|c|}
\hline Capacidad Básica & Indicador & Formula & Resultado \\
\hline \multirow{2}{*}{$\begin{array}{l}\text { Integridad } \\
\text { Física }\end{array}$} & $\begin{array}{c}\% \text { de mujeres rurales } \\
\text { con jefatura femenina de } \\
\text { familias monoparentales } \\
\text { con acceso a programas } \\
\text { de salud sexual y } \\
\text { reproductiva }\end{array}$ & 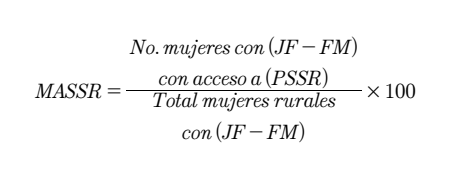 & $55 \%$ \\
\hline & $\begin{array}{l}\% \text { de mujeres rurales } \\
\text { con jefatura femenina de } \\
\text { familias monoparentales } \\
\text { que cotizan seguridas } \\
\text { social }\end{array}$ & $M C S S=\frac{\begin{array}{c}\text { No. mujeres rurales con }(J F-F M) \\
\text { cot } \text { izan salud y pensión }\end{array}}{\begin{array}{c}\text { No. mujeres rurales con } \\
(J F-F M) \text { ocupadas }\end{array}} \times 100$ & $18 \%$ \\
\hline
\end{tabular}

Fuente: resultados de la encuesta 001 implementada en julio de 2016 en la vereda La Llanerita de Villavicencio, Meta.

\section{Control sobre su propio entorno}

- Ninguna de las mujeres rurales de la vereda se encuentra en la informalidad.

- El ingreso promedio de las mujeres jefe de hogar es de \$231.288 teniendo en cuenta que no se obtuvo información de los ingresos de todas las mujeres de la vereda.

Figura 13. Título de propiedad de tierra

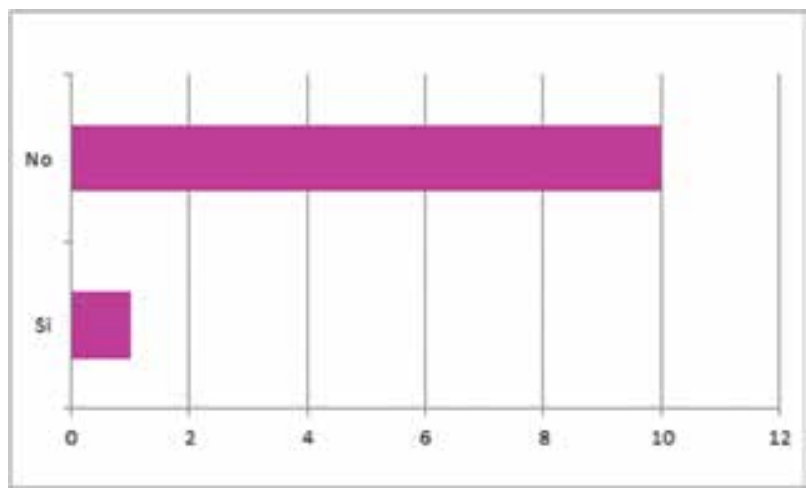

Fuente: resultados de la encuesta 001 implementada en julio de 2016 en la vereda La Llanerita de Villavicencio, Meta.

El DANE en la séptima entrega del Censo Nacional Agropecuario (2014) indicó que: 
las mujeres productoras se caracterizaron que por tener mayor proporción de Unidad Productora Agropecuaria (UPA) pero de menor tamaño; mientras que los hombres tienen mayor proporción de UPA de mayores tamaños. Del total de UPA con solo mujeres productoras, el 78,4\% tienen menos de 5 ha, y ocuparon el $9,5 \%$ del área; y donde los hombres son productores estas son menor en número $(66,8 \%)$ y área (4,9\%). En las UPA entre 5 y 100 ha se encontró menor participación de las UPA de mujeres productoras y mayor proporción en área (p. 10).

Diez (10) mujeres refieren no tener títulos de propiedad de tierra, ya que no poseen los recursos para adquirir bienes e inmuebles, es por eso que las actividades económicas a las que se dedican no son agrícolas (figura 14).

La vivienda que habitan para siete (7) mujeres es familiar, dos (2) es en arriendo y una (1) propia. Se evidencia que la mayoría de las mujeres cuentan con redes de apoyo que les permite vivir su cotidianidad en condiciones apropiadas.

Figura 14. Vivienda que habita

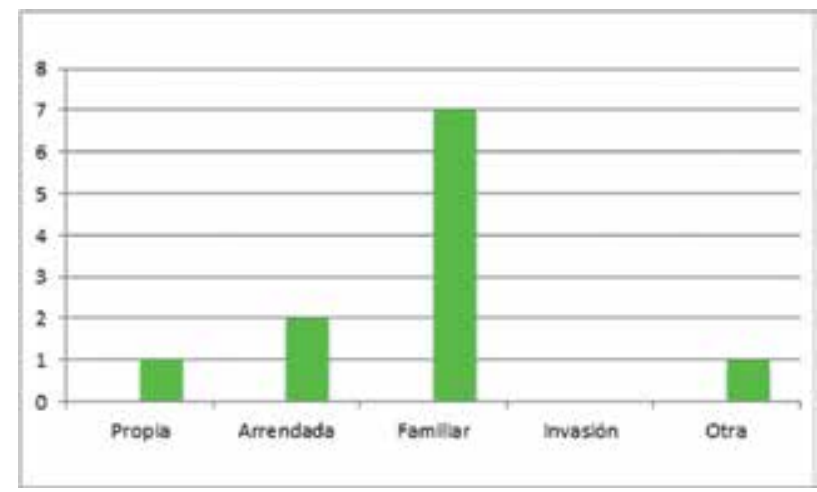

Fuente: resultados de la encuesta 001 implementada en julio de 2016 en la vereda La Llanerita de Villavicencio, Meta.

El ladrillo es el material que predomina en las casas que habitan. Estas mujeres esperan a futuro la posibilidad de adquirir una vivienda. Una de ellas indica que se encuentra en condición de desplazamiento, por lo cual espera la reparación y así acceder a una vivienda propia.

Cifras de la Unidad para la Atención y Reparación Integral a las Víctimas estiman que a la fecha hay 7.028.776 personas desplazadas, producto de la violencia, de las cuales 3.481.244, es decir, el $49.5 \%$ de la población total de víctimas del conflicto armado son mujeres (USAID, Organización Internacional para las Migraciones, Unidad para la Atención y Reparación Integral a las Víctimas, s.f. p. 16). 
Otra mujer indica que ya cuenta con el lote propio y espera tener los recursos suficientes para su construcción.

Figura 15. Material de la casa que habita

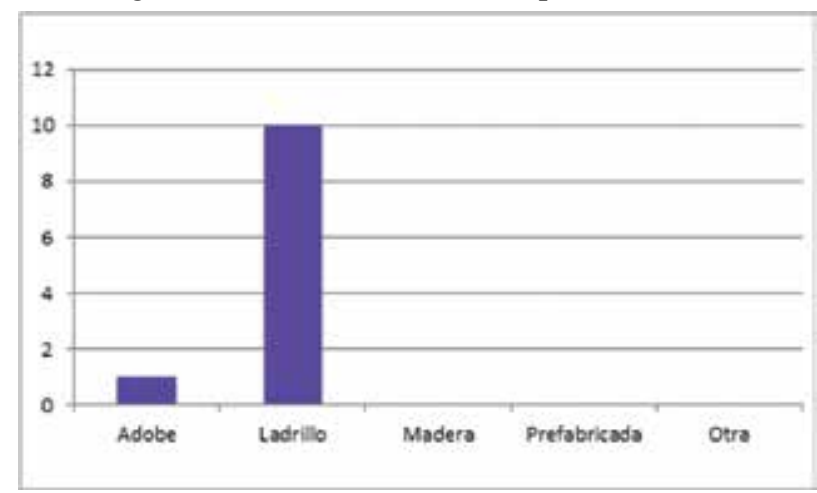

Fuente: resultados de la encuesta 001 implementada en julio de 2016 en la vereda La Llanerita de Villavicencio, Meta.

Siete (7) mujeres afirman tener experiencia crediticia. Lo que refiere que han tenido acceso a los servicios financieros, aunque no cuenten con estabilidad laboral e ingresos suficientes. No obstante, se podría asumir que los créditos obtenidos permiten pagar deudas anteriores, más no para emprendimiento. Así mismo, seis (6) mujeres afirman haber tenido capacitaciones sobre el sector rural, pero no ha sido posible ponerlo en práctica para mejorar sus ingresos

Sen (2000) indica que, la desigualdad de género es el resultado de haber excluido a millones de personas del acceso a bienes y recursos productivos, tales como la tierra, la tecnología y el conocimiento. Son, ante todo, consecuencia de las políticas económicas, sociales y comerciales que se han implementado.

Esta capacidad, es explicada en este relato:

La mayoría pagamos arriendo, entonces no tenemos el terreno para tener la vaca. Llegó un programa a la vereda, creo que ayer, de huertas y que le daban pollos, pero todos no los podíamos aceptar porque usted tiene su casa, pero entonces usted me la arrendó a mí, entonces usted me pide y yo para dónde me llevo la vaca o el pollo, yo para dónde lo llevo. Es por eso porque no hay el espacio, y digamos que vamos a hacer un cultivito allí, igual lo mismo no es mío (Entrevista, M4).

Los resultados de esta capacidad son: 
Tabla 16. Resultado de la capacidad Control sobre su propio entorno

\begin{tabular}{|c|c|c|c|}
\hline Capacidad Básica & Indicador & Formula & Resultado \\
\hline \multirow{7}{*}{$\begin{array}{l}\text { Control sobre su } \\
\text { propio entorno }\end{array}$} & $\begin{array}{l}\% \text { de mujeres rurales } \\
\text { con jefatura femenina de } \\
\text { familias monoparentales } \\
\quad \text { en la informalidad }\end{array}$ & 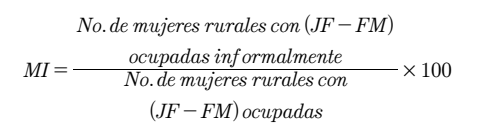 & 0 \\
\hline & $\begin{array}{l}\text { Nivel de ingresos } \\
\text { mensuales monetarios } \\
\text { mujeres rurales con } \\
\text { jefatura femenina de } \\
\text { familas monoparentales }\end{array}$ & $\begin{array}{c}\text { Promedio ingresosmensuales } \\
\text { NIM }=\frac{\text { de mujeres rurales con }(\mathrm{JF}-\mathrm{FM})}{\text { Promedio de ingreos mensuales }} \times 100 \\
\text { de mujeres rurales }\end{array}$ & $\begin{array}{l}\text { indicador } \\
\text { no hallado } \\
\text { por falta de } \\
\text { información. }\end{array}$ \\
\hline & $\begin{array}{c}\% \text { de mujeres rurales } \\
\text { con jefatura femenina de } \\
\text { familias monoparentales } \\
\text { en desempleo }\end{array}$ & $\begin{array}{c}\text { No. de mujeres rurales } \\
T D M=\frac{\text { con }(J F-F M) \text { no ocupadas }}{\text { PEA de mujeres rurales }} \\
\operatorname{con}(J F-F M)\end{array}$ & $36 \%$ \\
\hline & $\begin{array}{c}\% \text { de mujeres rurales } \\
\text { con jefatura femenina de } \\
\text { familias monoparentales } \\
\text { con titulo de propiedad } \\
\text { de tierra }\end{array}$ & 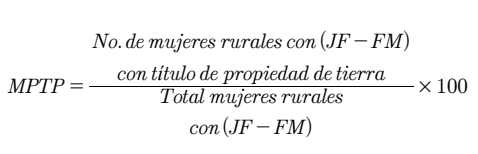 & $9 \%$ \\
\hline & $\begin{array}{l}\% \text { de mujeres rurales } \\
\text { con jefatura femenina de } \\
\text { familias monoparentales } \\
\text { con acceso a vivienda }\end{array}$ & 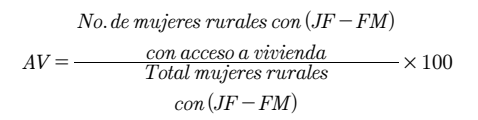 & $9 \%$ \\
\hline & $\begin{array}{l}\% \text { de mujeres rurales } \\
\text { con jefatura femenina de } \\
\text { familias monoparentales } \\
\text { con acceso a } \\
\text { financiamiento }\end{array}$ & $\begin{array}{c}\text { No. de mujeres }(J F-F M) \\
A F=\frac{\text { con acceso a financiación }}{\text { Total mujeres rurales }} \times 100 \\
\operatorname{con}(J F-F M)\end{array}$ & $64 \%$ \\
\hline & $\begin{array}{c}\% \text { de mujeres rurales } \\
\text { con jefatura femenina de } \\
\text { familias monoparentales } \\
\text { con acceso a } \\
\text { capacitación del sector } \\
\text { rural }\end{array}$ & $\begin{array}{c}\text { No. de mujeres con }(J F-F M) \\
A C=\frac{\text { con acceso a capacitación del } \sec t o r}{\text { Total mujeres rurales }} \\
\operatorname{con}(J F-F M)\end{array} \times 100$ & $55 \%$ \\
\hline
\end{tabular}

Fuente: resultados de la encuesta 001 implementada en julio de 2016 en la vereda La Llanerita de Villavicencio, Meta.

\section{Razón práctica}

Nussbaum (2002) refiere que son capaces de plasmar una concepción del bien y de comprometerse en una reflexión crítica acerca del planeamiento de su propia vida, la educación que es el eje central de los conceptos claros para construir las vivencias y diario vivir, se evidencia en las mujeres en sus discursos y claridad en conocimientos, pues aunque todas son bachilleres, sí es necesario ampliar las habilidades para fomentar sus opciones de trabajo y emprendimiento. 
En conclusión, el resultado obtenido de la capacidad Razón práctica es:

Tabla 17. Resultado de la capacidad Razón práctica

\begin{tabular}{|c|c|c|c|}
\hline Capacidad Básica & Indicador & Formula & Resultado \\
\hline & $\begin{array}{l}\% \text { de mujeres rurales } \\
\text { con jefatura femenina de } \\
\text { familias monoparentales } \\
\text { alfabetizadas }\end{array}$ & 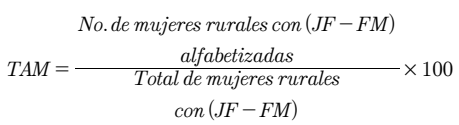 & $100 \%$ \\
\hline Razón práctica & $\begin{array}{l}\% \text { de mujeres } \\
\text { rurales con jefatura } \\
\text { femenina de familias } \\
\text { monoparentales que } \\
\text { integran organizaciones } \\
\text { gremiales o } \\
\text { comunitarias }\end{array}$ & 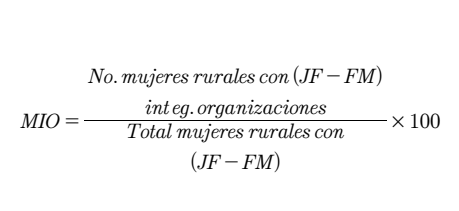 & $36 \%$ \\
\hline
\end{tabular}

Fuente: resultados de la encuesta 001 implementada en julio de 2016 en la vereda La Llanerita de Villavicencio, Meta.

Esta capacidad se evidencia en la crianza que ellas como mamá y papá han inculcado en su proceso de formación:

...yo les he enseñado a ellos el respeto y el quererse, la autoestima para ellos, porque si ellos no se quieren, no se respetan; no van a querer a nadie ni van a respetar a nadie... (Grupo Focal, Mujer No. 5).

...tanto como uno de ser cabeza de hogar como a los hijos de uno de "por qué no tienen papá", entonces todos quieren lavarse las manos con los hijos de uno, "que porque no tienen papá", entonces son los hijos de fulana, a veces hace falta, entonces siempre los van discriminando como a uno, como a los hijos de uno... (Grupo Focal, Mujer No. 7).

\section{Sentidos, imaginación y pensamiento}

Nussbaum (2002) define esta capacidad como la posibilidad de utilizar los sentidos, la imaginación, el pensamiento y la razón para que a partir de una buena educación pueda tener experiencias placenteras, evitar el sufrimiento innecesario y poder vivir conforme sus posibilidades.

Esta capacidad fue medida a través del estrés pues este problema impide utilizar los sentidos, imaginación y el pensamiento para generar soluciones y posibilidades; además es el problema que más han sufrido cinco (5) mujeres rurales de la vereda, violencia intrafamiliar indican tres (3) mujeres, y dos (2), depresión. De los problemas sufridos cuatro (4) afirman no haber hecho nada para superarlos, tres asistieron al médico, y una ha asistido a programas de salud, una (1) medicación y, una (1) sin respuesta. 
Figura 16. Problemas sufridos

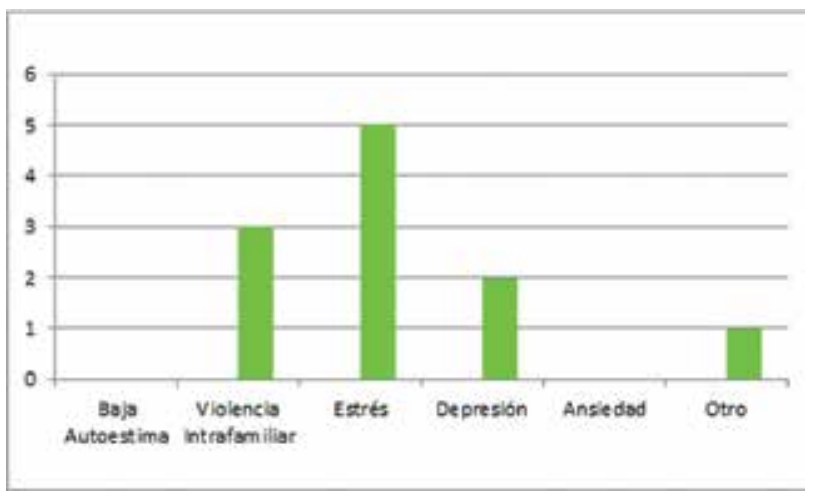

Fuente: resultados de la encuesta 001 implementada en julio de 2016 en la vereda La Llanerita de Villavicencio, Meta.

En conclusión, para las mujeres rurales de la vereda, la capacidad de sentidos, imaginación y pensamiento es la posibilidad de expresarse, comunicarse con los demás y generar relaciones humanas. El resultado del indicador es:

Tabla 18. Resultado de la capacidad Sentidos, imaginación y pensamiento

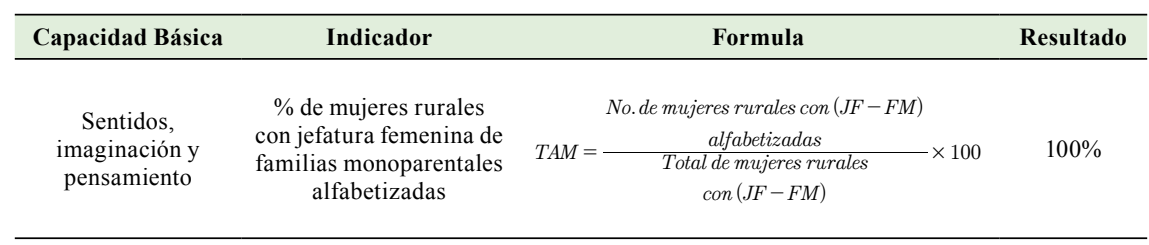

Fuente: resultados de la encuesta 001 implementada en julio de 2016 en la vereda La Llanerita de Villavicencio, Meta.

Los relatos expresan:

'con una mano se le da amor y con la otra rejo' uno no necesita un hombre para poder criar a un hijo (Grupo Focal, Mujer No. 6).

...créame que si yo, en caso de que fuera mala madre y me decidiera separar de mi hogar le doy mis hijos a mi marido yo trabajo y le doy los $\$ 80.000$, pero lo haría para que él sepa qué es llevar la carga de tener un hijo, la educación, el descanso, todo, ¿sí? Pero entonces sí es necesario (Grupo Focal, Mujer No. 5).

\section{Otras especies}

Tan solo cuatro mujeres realizan actividades de recreación y deporte (figura 17). Además, en cuanto a la imagen que representan para sus hijos son de respeto, autoridad, admiración, apoyo y amor. Las principales enseñanzas que las mujeres les 
han inculcado a sus hijos ha sido el respeto por los demás, el respeto por las niñas, el amor por sus hermanos, autoestima, respeto a los animales, que los cuiden, que no sean agresivos con ellos, respeto a la naturaleza, de no botar basura.

Figura 17. Práctica de actividades de recreación y deporte

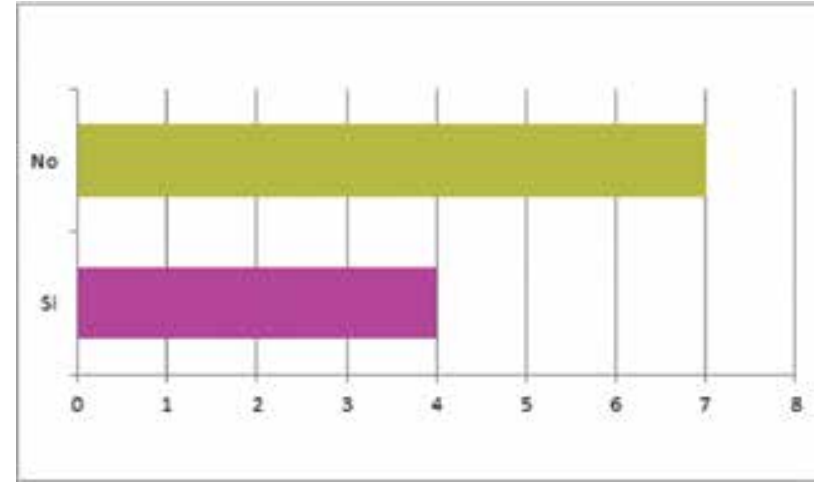

Fuente: resultados de la encuesta 001 implementada en julio de 2016 en la vereda La Llanerita de Villavicencio, Meta.

Ellas indican que no han tenido ningún tipo de problemas en la vereda con nadie, pues excepto con el papá de los hijos, y el conflicto armado ha incidido en sus decisiones y a su vez no han contado con ayuda del Estado.

Para la capacidad de otras especies, el resultado es:

Tabla 19. Resultado de la capacidad Otras especies

\begin{tabular}{|c|c|c|c|}
\hline Capacidad Básica & Indicador & Formula & Resultado \\
\hline Otras especies & $\begin{array}{l}\% \text { de mujeres rurales } \\
\text { con jefatura femenina de } \\
\text { familias monoparentales } \\
\text { que participan } \\
\text { en actividades de } \\
\text { recreación y deporte }\end{array}$ & 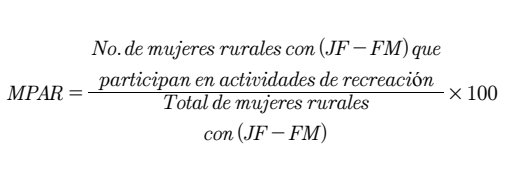 & $36 \%$ \\
\hline
\end{tabular}

Fuente: resultados de la encuesta 001 implementada en julio de 2016 en la vereda La Llanerita de Villavicencio, Meta.

\section{0) Juego}

El cuidado para las mujeres rurales es básicamente mantener una imagen arreglada, su autoestima elevada, pues al no contar con ingresos suficientes destinan el dinero a otras prioridades, especialmente los hijos. La mujer es la imagen personal del hogar, siendo el eje de la casa y ejemplo de los hijos; no necesariamente se debe tener dinero para quererse y para cuidarse. 
Según Nussbaum (2002) hace referencia a que todas las personas puedan disfrutar de la vida en todo su esplendor, para la presente investigación se tomó la pregunta de la participación de las mujeres jefes de hogar en actividades de recreación como marco para realizar actividades de descanso y disfrute, así como la oportunidad de tener tiempo de para ellas mismas (figura 17).

Los resultados para esta capacidad son:

Tabla 20. Resultado de la capacidad Juego

\begin{tabular}{|c|c|c|c|}
\hline Capacidad Básica & Indicador & Formula & Resultado \\
\hline \multirow{2}{*}{ Juego } & $\begin{array}{l}\% \text { de mujeres rurales } \\
\text { con jefatura femenina de } \\
\text { familias monoparentales } \\
\text { que participan } \\
\text { en actividades de } \\
\text { recreación y deporte }\end{array}$ & $\begin{array}{c}\text { No. de mujeres rurales con }(J F-F M) \text { que } \\
\text { MPAR }=\frac{\text { participan en actividades de recreación }}{\text { Total de mujeres rurales }} \\
\operatorname{con}(J F-F M)\end{array} \times 100$ & $36 \%$ \\
\hline & $\begin{array}{c}\text { No. de programas de } \\
\text { autoestima, manejo } \\
\text { de estrés, manejo de } \\
\text { depresión de mujeres } \\
\text { rurales con jefatura } \\
\text { femenina de familias } \\
\text { monoparentales }\end{array}$ & $\begin{array}{l}\text { Programas de autoestima, manejo de estrés, } \\
\text { depresión a los que han asistido las mujeres } \\
\text { rurales con (JF-FM) en los últimos tres (3) años }\end{array}$ & $\begin{array}{c}\text { No } \\
\text { encontrado }\end{array}$ \\
\hline
\end{tabular}

Fuente: resultados de la encuesta 001 implementada en julio de 2016 en la vereda La Llanerita de Villavicencio, Meta.

Las mujeres definen el tiempo libre así:

...salgo como "volador sin palo", en un tiestico de moto, primero voy a donde está la niña, no es lo único, pero es lo más importante para mí. El tiempo libre para mí, lo más chévere y lo más divertido es rascarnos el ombligo, pero los tres (Grupo Focal, Mujer No. 4).

...el domingo sí me la paso todo el día con el niño, porque él me dice que el domingo no trabaje que me la pase con el niño, "que vaya con el niño a tal lado, venga y le doy para el juego, o venga y lo trae a piscina" porque hay unas cabañas y "venga y traiga al niño a piscina"... (Entrevista, Mujer No. 10).

\section{Discusión}

Este documento se diferencia de otras investigaciones en que toma los dos métodos, cuantitativo y cualitativo (entrevista, grupo focal y encuesta), con ello se hizo la triangulación entre teoría, resultados y apreciación de las investigadoras.

La presente investigación llega hasta la caracterización de la muestra estudiada dejando pendiente la formulación de proyectos de emprendimiento y contacto con entidades gubernamentales para poder presentar la propuesta. 


\section{Conclusiones}

En la presente investigación se pudo evidenciar que ninguna mujer se definió a sí misma como mujer rural, por ende, no existe un empoderamiento ni reconocimiento de su condición, impidiendo de esta manera poderla vivir. Además, por no tener título de propiedad de tierra, son muy pocas las opciones de realizar proyectos productivos dentro de la zona, ya que en la vereda La Llanerita se evidencian actividades económicas de turismo en los hoteles y villas del sector habitualmente en temporadas altas de vacaciones y actividades de recreación. Los salarios pagados son por hora/ labor y no se estiman en salarios mínimos legales.

Un aspecto importante que se debe recalcar, es que la situación de las familias con jefatura femenina está condicionada por factores como: el estado civil de las jefas, el ciclo vital de las familias, las redes familiares y sociales de apoyo, el sistema de seguridad social, la legislación familiar y las políticas públicas.

Por ende, es necesaria una política social que brinde apoyos institucionales dirigidos hacia las mujeres jefes de hogar que permitan contrarrestar las desigualdades sociales, además una legislación que establezca la responsabilidad masculina hacia los hijos e incentive la responsabilidad económica.

Por último, podemos decir que aunque estas mujeres viven con limitantes en su día a día, viven felices, orgullosas de sí mismas, de sus hijos como su principal motor para salir adelante.

\section{Referencias}

Alcaldía de Villavicencio. (2015). www.villavicencio.gov.co. Recuperado el 18 de 05 de 2016, de http://www.villavicencio.gov.co/index.php?option=com docman\&task=cat_view\&gid=1649\&Itemid=209

Allende, I., \& Franco, P. (s.f). Número 32: Pobreza y la exclusión social. Las mujeres primero. Revista con la a, 42.

Álvarez, O. (s.f). Informalidad laboral: Situación de las mujeres en Colombia. Recuperado de http:/www.colombianistas.org/Portals/0/Congresos/ Documentos/CongresoXVIII/Alvarez_Oriana_Sofia.pdf

Arriagada, I. (2001). Familias latinoamericanas. Diagnóstico y políticas públicas en los inicios del nuevo siglo. Santiago de Chile, Chile: CEPAL. División de Desarrollo Social.

Braidotti, R. (1991). Teorías de los estudios sobre la mujer: algunas experiencias contemporáneas en Europa. Historia y fuente oral, 3-17. 
Comisión Económica para América Latina y el Caribe (CEPAL). (2015). Recuperado el 13 de 3 de 2016 de http://www.cepal.org/es/notas/estados-deben-respondernecesidades-cambios-familias-latinoamericanas-sus-integrantes

Departamento Administrativo Nacional de Estadística - DANE. (2005). Censo General 2005. Jefatura de Hogar. Bogotá D.C., Colombia.

Departamento Administrativo Nacional de Estadística - DANE. (2014). Censo Nacional Agropecuario. Séptima entrega de resultados 2014. Bogotá D.C. Colombia.

Departamento Administrativo Nacional de Estadística - DANE. (2014). Censo Nacional Agropecuario 2014. Caracterización de los productores residentes en el área rural dispersa censada. Bogotá D.C. Colombia.

Departamento Administrativo Nacional de Estadística - DANE. (2015). Encuesta Nacional de Calidad de Vida - 2015. Bogotá D.C., Colombia.

Díaz, D. (2002). Situación de la mujer rural colombiana. Perspectiva de género. Bogotá. Colombia.

CEPAL. (2015). Panorama social de América Latina 2015.

Echeverri, L. (1994). Tendencias o rupturas de la familia colombiana. Una mirada retrospectiva y prospectiva. Bogotá D.C., Colombia: Universidad Nacional.

Congreso de Colombia. (2002). Ley 731 del 14 de enero de 2002. Bogotá D.C., Colombia.

Escamilla, D., Parra, Y., Sepúlveda, M., \& Vásquez, V. (2013). Familias monoparentales, madres solteras jefas de hogar (Chile). Entrevistas. Concepción, Chile: Universidad del Biobío.

Farah, M., \& Pérez, E. (2003). Mujeres rurales y nueva ruralidad en Colombia. II Congreso Iberoamericano de Estudios de Género. Salta, Argentina

Fraser, N. (1997). Iustia Interrrupta. Santafé de Bogotá: Siglo del Hombre Editores.

Geldstein, R., y Nena, D. (1994, enero-marzo). Mujeres como principal sostén económico del hogar. Boletín Informativo Techint, 277, 51-80.

Geldstein, R. (1997). Mujeres jefas de hogar: familia, pobreza y género. Buenos Aires: UNICEF Argentina.

Hernández, R., Fernández, C., \& Baptista, P. (2012). Metodología de la investigación (4 ${ }^{\mathrm{a}}$ ed.). México D.F.: McGraw-Hill Interamericana.

Instituto Colombiano de Bienestar Familia. (1988). Ley 30 de 1988. Bogotá D.C., Colombia. 
Instituto Colombiano de Bienestar Familiar (ICBF). Dirección de Prevención. (2012). Caracterización de las familias en Colombia. Bogotá D.C., Colombia.

Naciones Unidas. (1993). Conferencia Mundial de Derechos Humanos. Declaración y programa de acción de Viena. Viena, Austria.

Nussbaum, M. (2002). Las mujeres y el desarrollo humano. Herder.

Organización Internacional para las Migraciones, Unidad para la Atención y Reparación Integral a las Víctimas - USAID. (s.f.). Mujeres y conflicto armado.

República de Colombia. (1991). Constitución Política de Colombia de 1991.

Sancho, J., Martínez, J., \& Martín, M. (2002). Necesidad de un marco jurídico para el desarrollo rural de España. Madrid, España: Consejo Superior de Investigaciones Científicas CSIC. Instituto de Economía y Geografía.

Segura, N., \& Meerten, D. (1997). Desarraigo, género y desplazamiento interno en Colombia. Nueva Sociedad, 20.

Sen, A. (2000). Desarrollo y libertad. Planeta.

Válcarcel-Resalt, G. (1995). Desarrollo rural con enfoque local. Desarrollo sustentable. Madrid, España: Departamento de Economía del IEG. Recuperado de www.fao.org/docrep/010/a0825s/a0825s00.htm 